\title{
Miktoarm Star Polymer Based Multifunctional Traceable Nanocarriers for Efficient Delivery of Poorly Water Soluble Pharmacological Agents $^{\mathrm{a}}$
}

\author{
Ghareb M. Soliman, Rocio Redon, Anjali Sharma, Diana Mejía, \\ Dusica Maysinger, ${ }^{*}$ Ashok Kakkar*
}

A versatile methodology to develop an inherently fluorescent and thus traceable multifunctional nanodelivery platform based on miktoarm polymers is reported. Miktoarm stars containing covalently linked tetraiodofluorescein dye, polyethylene glycol, and polycaprolactone self-assemble into micelles, and integrate multiple functions including fluorescent tags for imaging, a hydrophobic core for drug incorporation, and a hydrophilic corona for micelle stabilization. Curcumin, a pleiotropic but very poorly water-soluble drug, is loaded into these micelles with an efficiency of 25-60 wt\%. It leads to a 25000 -fold increase in its aqueous solubility, and a sustained release over a period of $7 \mathrm{~d}$. These micelles are rapidly internalized into murine J774A.1 macrophages, and accumulated into discrete cellular compartments, whereas the free and physically encapsulated dye is diffused in the cytoplasm. Curcumin-loaded micelles reduce lipopolysaccharide-induced nitric oxide release. The studies establish miktoarm star based nanocarriers as highly efficient in tracking their fate and expanding the scope of pharmacological agents with limited utility in experimental medicine.
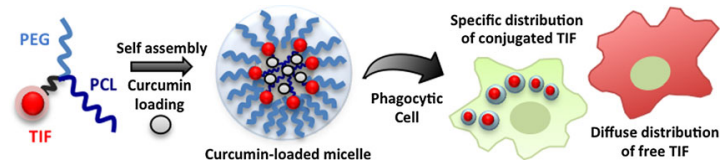

Dr. G. M. Soliman, Dr. R. Redon, A. Sharma, Dr. A. Kakkar

Department of Chemistry, McGill University, 801 Sherbrooke St.

West, Montreal, Quebec, Canada H3A oB8,

E-mail: ashok.kakkar@mcgill.ca

Dr. G. M. Soliman, D. Mejía, Dr. D. Maysinger

Department of Pharmacology and Therapeutics, McGill

University, 3655 Promenade Sir-William-Osler, Montreal, Quebec,

Canada $\mathrm{H}_{3} \mathrm{G} 1 \mathrm{Y} 6$,

E-mail: dusica.maysinger@mcgill.ca

Dr. G. M. Soliman

Department of Pharmaceutics, Faculty of Pharmacy, Assiut

University, 71526 Assiut, Egypt

Dr. R. Redon

Centro de Ciencias Aplicadas y Desarrollo Tecnológico,

Universidad Nacional Autónoma de México, Cd. Universitaria A.P.

70-186, C.P. 04510, Coyoacan, México D. F., México

${ }^{a}$ Supporting Information is available online from the Wiley Online Library or from the author.

\section{Introduction}

Multifunctional nanocarriers that can physically entrap hydrophobic drugs and other biologically active molecules, enhance their solubility, provide a controlled and sustained release, as well as help trace their cellular localization, constitute a topical area of research. ${ }^{[1-5]}$ Amphiphilic macromolecules self-assembled into nanoparticles have been widely studied in this regard. ${ }^{[6,7]}$ To monitor their accumulation at targeted sites, fluorescent dyes are often co-encapsulated into the hydrophobic core.$^{[8]}$ For efficiently tracing drug carriers, fluorescent dyes must be covalently bound to the micelle-forming macromolecules. Miktoarm polymers are a fairly recent addition to the polymer family and offer distinct advantages for pharmaceutical applications. ${ }^{[9-12]}$ These star-shaped polymers self-assemble into a 
unique architecture, where covalently bound hydrophilic arms constitute the corona and hydrophobic arms form the core of the micelles. The ease in synthetic articulation of the branched architecture of miktoarm stars makes them an attractive platform for developing multifunctional nanomaterials in which a fluorescent dye can be covalently stitched to the core. The self-assembled structures from these miktoarm stars can be used to encapsulate therapeutic agents with poor pharmacokinetic properties, while their inherent fluorescence can help track and determine the fate of these nanocarriers.

Curcumin is a low molecular weight hydrophobic polyphenol derived from the rhizome of turmeric (Curcuma longa $L$.), and is widely used as a yellow coloring agent for food and cosmetics. ${ }^{[13,14]}$ The pharmaceutical interest in curcumin is driven by its broad spectrum of pharmacological and biological activities, such as antioxidant, antiinflammatory, antimicrobial, anti-tumor, antidepressant and anti-HIV. ${ }^{[15]}$ Curcumin has many different targets, including the inflammatory enzymes COX-2 and iNOS, and is known to inhibit the IKK signaling pathway that is responsible for the phosphorylation of IKB-, an integral step in the activation of the pro-inflammatory transcriptor NF-kB. ${ }^{[14,16]}$ Curcumin has also been shown to inhibit the activity of iNOS in macrophages in the concentration range of $1-20 \mu \mathrm{M}^{[17]}$

Clinical studies have established the safety of curcumin for human use even at very large doses, as high as $12 \mathrm{~g} \mathrm{~d}^{-1} \cdot{ }^{[18-23]}$ Despite these promising properties, clinical utility of curcumin is limited due to its poor physicochemical properties including very low water solubility $\left(11 \mathrm{ng} \mathrm{mL}^{-1}\right)$ and poor stability at alkaline $\mathrm{pH}^{\left[{ }^{[24,25]} \mathrm{In}\right.}$ addition, extensive intestinal and hepatic metabolism and rapid elimination from the circulation result in poor bioavailability. ${ }^{[24]}$ There has been tremendous interest in overcoming these pharmacokinetic limitations in order to improve the clinical efficacy of curcumin, and a variety of delivery systems, including polymeric micelles, solid lipid nanoparticles, liposomes, cyclodextrins, biodegradable hydrogels, and solid dispersions have been investigated. ${ }^{[25-29]}$

We report herein the design and construction of a traceable nanodelivery platform based on $A B C$ type miktoarm stars in which the fluorescent dye tetraiodofluorescein (TIF) was covalently linked to a branched core together with polyethylene glycol (PEG) and polycaprolactone (PCL). These miktoarm stars self-assemble into micelles in an aqueous medium, into which curcumin was physically encapsulated with high efficiency. We demonstrate that there is a 25000 -fold increase in curcumin solubility upon loading into these nanocarriers, and its release is sustained over a period of $7 \mathrm{~d}$. The inherently fluorescent nanocarriers were rapidly internalized into J774A.1 murine macrophages, and were seen as distinct puncta as compared to the diffused free and physically incorporated dye. The anti-inflammatory properties of curcumin-loaded micelles were evaluated in macrophages activated by lipopolysaccharides (LPS). LPS is an endotoxin produced by Gram-negative bacteria, and it is commonly used to induce inflammation in vivo and to stimulate production of inflammatory biomarkers in vitro. ${ }^{[30,31]}$ The nanocarriers loaded with curcumin reduce LPS induced nitric oxide release in stressed macrophages, suggesting the retention of curcumin anti-inflammatory property.

\section{Experimental Section}

\subsection{Materials}

Water was deionized using a Millipore Milli-O system. Curcumin, lipopolysaccharides (L2630 Lot\# 012M4098V), 3-(4,5-dimethylthiazol-2-yl)-2,5-diphenyl tetrazolium bromide (MTT), $\varepsilon$-caprolactone (99\%), tin (II) 2-ethylhexanoate (95\%), copper (II) sulfate pentahydrate $\left(\mathrm{CuSO}_{4} \cdot 5 \mathrm{H}_{2} \mathrm{O}\right)(>98.0 \%)$, sodium ascorbate (NaAsc, crystalline, 98\%), tetrabutylammonium fluoride $\left(\mathrm{Bu}_{4} \mathrm{NF} ; 1 \mathrm{M}\right.$ in $\left.\mathrm{THF}\right)$, 11-bromo-1-undecanol (98\%), tetrabromomethane $\left(\mathrm{CBr}_{4} ; 99 \%\right)$, sodium azide $\left(\mathrm{NaN}_{3} ;>99.5 \%\right)$, and propargyl bromide solution (80 wt\% in toluene) were purchased from Sigma-Aldrich, St. Louis, MO, and used as received. Tetraiodofluorescein (TIF) was purchased from TCI (Tokyo Chemical Industry Co. Ltd.). All reactions were performed under dry conditions in an inert atmosphere using distilled solvents. Flash chromatography was performed using $60 \AA$ (230-400 mesh) silica gel from EMD Chemicals Inc. Dialysis membranes (Spectra/por, MWCO: 6-8 kDa, unless otherwise indicated) were purchased from Fisher Scientific (Rancho Dominguez, CA). Penicillin, streptomycin, Griess reagent (1\% sulfanilamide, $0.1 \%$ $N$-(1-naphthyl)-ethylenediaminedihydrochloride, and 5\% phosphoric acid), and fetal bovine serum were purchased from Invitrogen (Carlsbad, CA). $\varepsilon$-Caprolactone was dried over calcium hydride for $24 \mathrm{~h}$ and distilled under reduced pressure prior to use.

\subsection{Synthesis and Characterization of ABC Miktoarm Polymers}

Compounds $\mathbf{1}$ and $\mathbf{2}$ were synthesized by an adaptation of our previously published procedures. ${ }^{[11]}$ Monopropargylated tetraiodofluorescein was synthesized using a literature procedure. ${ }^{[32,33]}$

\subsubsection{Compound 3a}

To a solution of compound 2 with PEG chain length of $750 \mathrm{D}(0.725 \mathrm{~g}$, $0.630 \mathrm{mmol})$ in DMF $(1 \mathrm{~mL})$, sodium azide $\left(\mathrm{NaN}_{3}, 0.205 \mathrm{~g}\right.$, $3.168 \mathrm{mmol}$ ) and $\mathrm{NBut}_{4} \mathrm{I}(0.936 \mathrm{~g}, 0.025 \mathrm{mmol})$ were added. The reaction mixture was left to stir at room temperature overnight. It was subsequently diluted with $\mathrm{H}_{2} \mathrm{O}(5 \mathrm{~mL})$ and extracted with DCM $(3 \times 10 \mathrm{~mL})$, and the organic phase was washed with brine $(2 \times 10 \mathrm{~mL})$. The organic layer was then dried over $\mathrm{Na}_{2} \mathrm{SO}_{4}$ and filtered. The solvent was removed under vacuum. The crude was then washed several times with hexanes and diethylether to

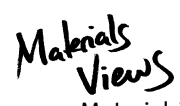

www.MaterialsViews.com 
remove excess of DMF. (0.57g, 77\% yield). ${ }^{1} \mathrm{H}$ NMR $(400 \mathrm{MHz}$, $\left.\mathrm{CDCl}_{3}\right): \delta \delta(\mathrm{ppm}) 1.00-1.30\left(\mathrm{~m}, 14 \mathrm{H},-\mathrm{CH}_{2}-\right), 1.40-1.49(\mathrm{~m}, 2 \mathrm{H}$, $\left.-\mathrm{CH}_{2}\right), 1.58-1.64\left(\mathrm{~m}, 2 \mathrm{H},-\mathrm{CH}_{2}\right), 1.70-1.85\left(\mathrm{~m}, 2 \mathrm{H},-\mathrm{CH}_{2}\right), 3.11$ (t, $\left.-\mathrm{CH}_{2} \mathrm{~N}_{3}\right), 3.23\left(\mathrm{~s}, 3 \mathrm{H},-\mathrm{OCH}_{3}\right), 3.37-3.52\left(\mathrm{~m},\left(-\mathrm{OCH}_{2} \mathrm{CH}_{2}-\right)_{n}\right), 3.78$ (t, $2 \mathrm{H},-\mathrm{CH}_{2} \mathrm{OCH}_{3}$ ), 4.25 (t, $2 \mathrm{H},-\mathrm{OCH}_{2} \mathrm{CH}_{2}$ triazole), 4.46 (br t, $2 \mathrm{H}$, $-\mathrm{OCH}_{2} \mathrm{CH}_{2}$ triazole), 4.62 (br s $2 \mathrm{H},-\mathrm{CH}_{2} \mathrm{OH}$ ), 7.67 (s, $1 \mathrm{H}, \mathrm{ArH}$ ), 7.70 (s, 1H, ArH), $7.82(\mathrm{~s}, 1 \mathrm{H}, \mathrm{ArH}), 8.02(\mathrm{~s}, 1 \mathrm{H}$, triazoleH), and $8.06(\mathrm{~s}, 1 \mathrm{H}$, triazoleH). ${ }^{13} \mathrm{C}\left\{{ }^{1} \mathrm{H}\right\}$ NMR (500 MHz, $\mathrm{CDCl}_{3}$ ): $\delta$ (ppm) 26.47, 26.67, 26.84, 28.80, 28.82, 28.99, 29.09, 29.31, 29.36, 30.31, 32.60, 45.20, 50.43, 50.47, 51.44, 59.05, 62.70, 69.43, 70.44, 70.51, 71.59, 71.91, $119.96,121.57,121.74,123.48,123.61,131.42,131.53,142.72$, 147.25, and 147.33.

\subsubsection{Compound $\mathbf{3 b}$}

Compound 2 with PEG chain length of $2 \mathrm{KD}(0.221 \mathrm{~g}, 0.098 \mathrm{mmol})$ in DMF $(1 \mathrm{~mL})$, sodium azide $\left(\mathrm{NaN}_{3}, 0.031 \mathrm{~g}, 0.484 \mathrm{mmol}\right)$ and $\mathrm{NBut}_{4} \mathrm{I}$ (1.43 mg, $0.004 \mathrm{mmol}$ ) were reacted together using similar procedure as described above. (0.1 g, 44\% yield). ${ }^{1} \mathrm{H}$ NMR $(400 \mathrm{MHz}$, $\left.\mathrm{CDCl}_{3}\right): \delta \delta(\mathrm{ppm}) 1.23-1.30\left(\mathrm{~m}, 16 \mathrm{H},-\mathrm{CH}_{2}-\right), 1.54\left(\mathrm{~m}, 2 \mathrm{H},-\mathrm{CH}_{2}\right)$, $1.91\left(\mathrm{~m}, 2 \mathrm{H},-\mathrm{CH}_{2} \mathrm{CH}_{2}\right.$ triazole), $3.20\left(\mathrm{t},-\mathrm{CH}_{2} \mathrm{~N}_{3}\right), 3.33(\mathrm{~s}, 3 \mathrm{H}$, $\left.-\mathrm{OCH}_{3}\right), 3.40-3.60\left(\mathrm{~m},\left(-\mathrm{OCH}_{2} \mathrm{CH}_{2}-\right)_{n}\right), 3.77\left(\mathrm{t}, 2 \mathrm{H},-\mathrm{CH}_{2} \mathrm{OCH}_{3}\right)$, 3.88 (t, $2 \mathrm{H},-\mathrm{CH}_{2} \mathrm{OCH}_{3}$ ), 4.36 (t, $2 \mathrm{H},-\mathrm{OCH}_{2} \mathrm{CH}_{2}$ triazole), 4.56 (br t, $2 \mathrm{H},-\mathrm{OCH}_{2} \mathrm{CH}_{2}$ triazole), 4.74 (br s $2 \mathrm{H},-\mathrm{CH}_{2} \mathrm{OH}$ ), 7.78 (s, $1 \mathrm{H}, \mathrm{ArH}$ ), $7.82(\mathrm{~s}, 1 \mathrm{H}, \mathrm{ArH}), 7.88(\mathrm{~s}, 1 \mathrm{H}, \mathrm{ArH}), 8.12(\mathrm{~s}, 1 \mathrm{H}$, triazoleH), and 8.19 (s, $1 \mathrm{H}$, triazoleH). ${ }^{13} \mathrm{C}\left\{{ }^{1} \mathrm{H}\right\} \mathrm{NMR}\left(500 \mathrm{MHz}, \mathrm{CDCl}_{3}\right): \delta \delta$ (ppm) 14.11, 22.61, $25.23,26.44,26.64,28.77,29.00,29.06,29.28,29.33,30.27,31.54$, $50.39,50.42,51.40,59.02,64.54,69.40,70.33,70.41,70.44,70.51$, $70.68,71.88,119.98,121.53,121.61,123.43,123.54,131.35,131.45$, $142.82,147.21,147.30$, and 161.16.

\subsubsection{Compound 4a $\left(\mathrm{PEG}_{750}-\mathrm{PCL}_{5700}-\mathrm{N}_{3}\right)$}

A solution of compound $\mathbf{3 a}(98 \mathrm{mg}, 0.089 \mathrm{mmol})$ in dry toluene $(2 \mathrm{~mL})$ was placed in a flame-dried two neck round bottom flask fitted with a condenser. The solution was degassed by evacuation, and distilled $\varepsilon$-caprolactone $(0.31 \mathrm{~mL}, 2.66 \mathrm{mmol})$ was added under nitrogen with a syringe through the rubber septum. A nitrogen purged solution of $\mathrm{Sn}$ (II) 2-ethylhexanoate ( $2 \mathrm{mg}, 0.005 \mathrm{mmol}$ ) in toluene $(1 \mathrm{~mL})$ was then added to the reaction flask, and the mixture was refluxed for $24 \mathrm{~h}$. The reaction mixture was then cooled to room temperature, and the solvent was removed under vacuum. The product was dissolved in dichloromethane and precipitated in cold methanol. The polymer was filtered and washed with diethylether to yield a white powder $(0.82 \mathrm{~g}, 76 \%$ yield). GPC: $\bar{M}_{\mathrm{n}}=6850 \mathrm{~g} \mathrm{~mol}^{-1}$, Polydispersity Index (PDI) $=1.30$. ${ }^{1} \mathrm{HNMR}\left(300 \mathrm{MHz}, \mathrm{CDCl}_{3}\right): \delta(\mathrm{ppm}) 0.80-1.68\left(\mathrm{~m}, 2 \mathrm{H},-\mathrm{CH}_{2}-\right)$ and $\left(\mathrm{m},-\mathrm{CH}_{2} \mathrm{PCL}\right), 2.10-2.34\left(\mathrm{~m},-\mathrm{CH}_{2} \mathrm{PCL}\right), 3.14\left(\mathrm{t},-\mathrm{CH}_{2} \mathrm{~N}_{3}\right), 3.31$ (s, $\left.3 \mathrm{H},-\mathrm{OCH}_{3}\right), 3.38-3.87\left(\mathrm{~m},\left(-\mathrm{OCH}_{2} \mathrm{CH}_{2}-\right) \mathrm{n}\right), 4.17\left(\mathrm{t}, 2 \mathrm{H},-\mathrm{CH}_{2} \mathrm{PCL}\right)$, $4.29\left(\mathrm{t}, 2 \mathrm{H},-\mathrm{OCH}_{2} \mathrm{CH}_{2}\right.$ triazole), 4.36 (t, $2 \mathrm{H},-\mathrm{OCH}_{2} \mathrm{CH}_{2}$ triazole), 5.13 (s, 2H, $-\mathrm{CH}_{2}$ PCL), 7.77 (s, $\left.1 \mathrm{H}, \mathrm{ArH}\right), 7.80$ (s, 1H, ArH), $7.90(\mathrm{~s}, 1 \mathrm{H}, \mathrm{ArH}), 8.08(\mathrm{~s}, 1 \mathrm{H}$, triazoleH), and $8.19(\mathrm{~s}, 1 \mathrm{H}$, triazoleH). ${ }^{13} \mathrm{C}\left\{{ }^{1} \mathrm{H}\right\}$ NMR $\left(300 \mathrm{MHz}, \mathrm{CDCl}_{3}\right): \delta$ (ppm) 0.94, 11.81, 13.90, 15.18, $22.54,22.61,24.50,25.26,25.33,25.38,25.45,25.49,25.51,28.03$, $28.19,28.26,28.33,29.30,29.56,31.74,34.03,34.16,34.25,34.47$, $36.46,39.45,45.08,47.30,50.41,58.94,62.16,62.34,62.93,63.74$, $63.87,63.97,64.07,64.22,65.55,65.78,69.40,70.23,70.46,71.82$, $76.67,77.70,120.09,121.54,122.59,124.82,124.92,131.59,137.29$, 146.81 , and 146.92 .

\subsubsection{Compound $\mathbf{4 b}\left(\mathrm{PEG}_{2000}-\mathrm{PCL}_{5200}-\mathrm{N}_{3}\right)$}

Compound $\mathbf{3 b}(66.3 \mathrm{mg}, 0.029 \mathrm{mmol})$ and $\varepsilon$-caprolactone $(0.10 \mathrm{~mL}$, $0.87 \mathrm{mmol}$ ) were reacted together using the above mentioned procedure for ring opening polymerization. (49 mg, 70\% yield) GPC: $\bar{M}_{\mathrm{n}}=7600 \mathrm{~g} \mathrm{~mol}^{-1}, \mathrm{PDI}=1.34 .{ }^{1} \mathrm{H} \mathrm{NMR}\left(300 \mathrm{MHz}, \mathrm{CDCl}_{3}\right): \delta(\mathrm{ppm})$ 0.80-1.68 (m, 20H, $\left.-\mathrm{CH}_{2}-\right)$ and $\left(\mathrm{m},-\mathrm{CH}_{2} \mathrm{PCL}\right), 2.10-2.34(\mathrm{~m}$, $\left.-\mathrm{CH}_{2} \mathrm{PCL}\right), 3.14\left(\mathrm{t},-\mathrm{CH}_{2} \mathrm{~N}_{3}\right), 3.31\left(\mathrm{~s}, 3 \mathrm{H},-\mathrm{OCH}_{3}\right), 3.38-3.87(\mathrm{~m}$, $\left(-\mathrm{OCH}_{2} \mathrm{CH}_{2}-\right) \mathrm{n}$ ), 4.17 (t, $\left.2 \mathrm{H},-\mathrm{CH}_{2} \mathrm{PCL}\right), 4.29$ (t, $2 \mathrm{H},-\mathrm{OCH}_{2} \mathrm{CH}_{2-}$ triazole), $4.36\left(\mathrm{t}, 2 \mathrm{H},-\mathrm{OCH}_{2} \mathrm{CH}_{2}\right.$ triazole), $5.13\left(\mathrm{~s}, 2 \mathrm{H},-\mathrm{CH}_{2} \mathrm{PCL}\right), 7.77$ (s, 1H, ArH), 7.80 (s, 1H, ArH), 7.90 (s, 1H, ArH), 8.08 (s, 1H, triazoleH), and 8.19 (s, $1 \mathrm{H}$, triazoleH). ${ }^{13} \mathrm{C}\left\{{ }^{1} \mathrm{H}\right\} \mathrm{NMR}\left(300 \mathrm{MHz}, \mathrm{CDCl}_{3}\right): \delta$ (ppm) $0.94,11.81,13.90,15.18,22.54,22.61,24.50,25.26,25.33,25.38$, $25.45,25.49,25.51,28.03,28.19,28.26,28.33,29.30,29.56,31.74$, $34.03,34.16,34.25,34.47,36.46,39.45,45.08,47.30,50.41,58.94$, $62.16,62.34,62.93,63.74,63.87,63.97,64.07,64.22,65.55,65.78$, $69.40,70.23,70.46,71.82,76.67,77.70,120.09,121.54,122.59$, $124.82,124.92,131.59,137.29,146.81$, and 146.92.

\subsubsection{Compound 4c $\left(\mathrm{PEG}_{2000}-\mathrm{PCL}_{21000}-\mathrm{N}_{3}\right)$}

Compound $\mathbf{3 b}(73.7 \mathrm{mg}, 0.03 \mathrm{mmol})$ and $\varepsilon$-caprolactone $(0.5 \mathrm{~mL}$, $4.510 \mathrm{mmol}$ ) were reacted together using the above mentioned procedure for ring opening polymerization. ( $0.63 \mathrm{~g}, 86 \%$ yield). GPC: $\bar{M}_{\mathrm{n}}=22720 \mathrm{~g} \mathrm{~mol}^{-1}, \mathrm{PDI}=1.44 .{ }^{1} \mathrm{H} \mathrm{NMR}\left(300 \mathrm{MHz}, \mathrm{CDCl}_{3}\right): \delta(\mathrm{ppm})$ 0.80-1.78 (m, 20H, $\left.-\mathrm{CH}_{2}-\right)$ and $\left(\mathrm{m},-\mathrm{CH}_{2} \mathrm{PCL}\right), 2.13-2.47$ $\left(\mathrm{m},-\mathrm{CH}_{2} \mathrm{PCL}\right), 3.25\left(\mathrm{t},-\mathrm{CH}_{2} \mathrm{~N}_{3}\right), 3.36\left(\mathrm{~s}, 3 \mathrm{H},-\mathrm{OCH}_{3}\right), 3.51-4.08$ $\left(\mathrm{m}, \quad\left(-\mathrm{OCH}_{2} \mathrm{CH}_{2}-\right) \mathrm{n}\right), 4.28$ (t, $\left.2 \mathrm{H},-\mathrm{CH}_{2} \mathrm{PCL}\right), 4.41$ (t, $2 \mathrm{H}$, $-\mathrm{OCH}_{2} \mathrm{CH}_{2}$ triazole), 4.61 (t, $2 \mathrm{H},-\mathrm{OCH}_{2} \mathrm{CH}_{2}$ triazole), 5.18 (s, $2 \mathrm{H}$, $\left.-\mathrm{CH}_{2} \mathrm{PCL}\right), 7.80$ (s, 1H, ArH), 7.84 (s, 1H, ArH), 7.89 (s, 1H, ArH), 8.09 (s, $1 \mathrm{H}$, triazoleH), and $8.22\left(\mathrm{~s}, 1 \mathrm{H}\right.$, triazoleH) ${ }^{13} \mathrm{C}\left\{{ }^{1} \mathrm{H}\right\} \mathrm{NMR}(300 \mathrm{MHz}$, $\left.\mathrm{CDCl}_{3}\right): \delta$ (ppm) 0.94, 11.81, 13.90, 13.93, 15.18, 22.55, 22.66, 24.50, $25.26,25.39,25.45,25.49,28.26,28.19,28.26,28.33,29.30,29.56$, $31.74,34.04,34.16,36.46,39.45,45.08,47.31,50.44,58.95,62.16$, $62.34,62.93,63.97,64.01,64.08,65.55,65.79,69.40,70.46,70.50$, 71.82 , 76.67, 120.09, 121.54, 122.59, 124.82, 124.92, 131.59, 137.29, 146.81 , and 146.92 .

\subsubsection{Compound 5a $\left(\mathrm{PEG}_{750}-\mathrm{PCL}_{5700}-\mathrm{TIF}\right)$}

Compound 4a $(42.6 \mathrm{mg}, 0.003 \mathrm{mmol}$ ) and monopropargylated tetraiodofluorescein $(2.61 \mathrm{mg}, 0.003 \mathrm{mmol})$ were dissolved in $3 \mathrm{~mL}$ of DMF, followed by the addition of sodium ascorbate $(0.5 \mathrm{mg}, 0.002 \mathrm{mmol})$. An aqueous solution ( $1 \mathrm{~mL}$ ) of $\mathrm{CuSO}_{4} \cdot 5 \mathrm{H}_{2} \mathrm{O}$ $(0.5 \mathrm{mg}, 0.002 \mathrm{mmol})$ was added dropwise to the solution. The reaction mixture was left to stir overnight at room temperature. Approximately, $30 \mathrm{~g}$ of ice was added to the remaining solution, and centrifuged at $4{ }^{\circ} \mathrm{C}$ for $15 \mathrm{~min}$, after which, the solid was decanted and washed with diethylether $(3 \times 30 \mathrm{~mL})$ and centrifuged after each diethylether addition, and upon decantation the solvent was evaporated to yield the product as a purple solid (25 mg, 55\% yield). ${ }^{1} \mathrm{H}$ NMR (300 MHz, CDCl3): $\delta$ (ppm) $0.87-1.64$ $\left(\mathrm{m}, 2 \mathrm{OH},-\mathrm{CH}_{2}-\right)$ and $\left(\mathrm{m},-\mathrm{CH}_{2} \mathrm{PCL}\right), 2.09-2.51\left(\mathrm{~m},-\mathrm{CH}_{2} \mathrm{PCL}\right), 3.21$ (t, $\left.-\mathrm{CH}_{2} \mathrm{PCL}\right), 3.37\left(\mathrm{~s}, 3 \mathrm{H},-\mathrm{OCH}_{3}\right), 3.46-3.66\left(\mathrm{~m},\left(-\mathrm{OCH}_{2} \mathrm{CH}_{2}-\right) \mathrm{n}\right)$, 3.81 (t, $\left.2 \mathrm{H},-\mathrm{CH}_{2} \mathrm{O}-\mathrm{Dye}\right), 4.29$ ( $\left.\mathrm{t}, 2 \mathrm{H},-\mathrm{CH}_{2} \mathrm{PCL}\right), 4.41$ (t, $2 \mathrm{H}$, $-\mathrm{OCH}_{2} \mathrm{CH}_{2}$ triazole), 4.61 (t, $2 \mathrm{H},-\mathrm{OCH}_{2} \mathrm{CH}_{2}$ triazole), 5.19 (s, $2 \mathrm{H}$, $-\mathrm{CH}_{2} \mathrm{PCL}$ ), 5.30 (s, 2H, $-\mathrm{OCH}_{2} \mathrm{PCL}$ ), 6.91 (s, 1H, ArH), 7.05 (s, 1H, $\operatorname{ArH}), 7.19$ (s, 1H, ArH), 7.28 (s, 1H, ArH), 7.45 (s, 1H, ArH), 7.61 (s, 2H, $\operatorname{ArH}), 7.83$ (s, 1H, ArH), 7.85 (s, 1H, ArH), 7.89 (s, 1H, ArH), 8.10 (s, 1H, 
triazoleH), and 8.23 (s, $1 \mathrm{H}$, triazoleH). ${ }^{13} \mathrm{C}\left\{{ }^{1} \mathrm{H}\right\}$ NMR $(300 \mathrm{MHz}$, $\left.\mathrm{CDCl}_{3}\right): \delta$ (ppm) 0.99, 11.85, 13.95, 15.26, 22.60, 24.40, 24.54, 24.66, $25.28,25.35,25.37,25.50,25.62,25.65,26.43,26.81,26.87,28.18$, $28.31,28.38,28.45,28.80,29.22,29.29,29.35,29.42,29.60,31.78$, $32.30,32.58,33.84,33.94,34.08,34.20,34.22$, 34.30, 36.57, 39.47, $45.17,47.34,63.78,63.96,64.12,64.27,65.84,69.47,70.49,70.53$, $71.89,119.21,119.98,121.46,122.60,124.87,124.98,131.63,131.71$, $137.32,146.89,147.00,173.30,173.54,173.63,174.00$, and 176.47.

\subsubsection{Compound $\mathbf{5 b}\left(\mathrm{PEG}_{2000}-\mathrm{PCL}_{5200}-\mathrm{TIF}\right)$}

Compounds $4 \mathbf{b}$ ( $49.7 \mathrm{mg}, 0.003 \mathrm{mmol}$ ), monopropargylated tetraiodofluorescein $(2.22 \mathrm{mg}, 0.002 \mathrm{mmol})$, sodium ascorbate $(0.5 \mathrm{mg}$, $0.002 \mathrm{mmol})$, and $\mathrm{CuSO}_{4} \cdot 5 \mathrm{H}_{2} \mathrm{O}(0.5 \mathrm{mg}, 0.002 \mathrm{mmol})$ were reacted together using above mentioned procedure. (0.32 g, 63\% yield). ${ }^{1} \mathrm{H}$ $\operatorname{NMR}\left(300 \mathrm{MHz}, \mathrm{CDCl}_{3}\right): \delta(\mathrm{ppm}) 0.90-1.58\left(\mathrm{~m}, 20 \mathrm{H},-\mathrm{CH}_{2}-\right)$ and $(\mathrm{m}$, $-\mathrm{CH}_{2} \mathrm{PCL}$ ), 2.09-2.69 (m, $\left.-\mathrm{CH}_{2} \mathrm{PCL}\right), 2.88\left(\mathrm{t},-\mathrm{CH}_{2} \mathrm{PCL}\right), 3.02(\mathrm{~s}, 3 \mathrm{H}$, $\left.-\mathrm{OCH}_{3}\right), 3.22-4.09\left(\mathrm{~m},\left(-\mathrm{OCH}_{2} \mathrm{CH}_{2}-\right)_{n}\right),\left(\mathrm{m}, 2 \mathrm{H},-\mathrm{CH}_{2} \mathrm{Br}\right), 4.32$ (t, $\left.2 \mathrm{H},-\mathrm{CH}_{2} \mathrm{O}-\mathrm{Dye}\right), 4.37\left(\mathrm{t}, 2 \mathrm{H},-\mathrm{CH}_{2} \mathrm{PCL}\right), 4.57$ (t, $2 \mathrm{H},-\mathrm{OCH}_{2} \mathrm{CH}_{2}$ triazole), 4.66 (t, $2 \mathrm{H},-\mathrm{OCH}_{2} \mathrm{CH}_{2}$ triazole), 5.15 (s, $2 \mathrm{H},-\mathrm{CH}_{2} \mathrm{PCL}$ ), 7.45 (s, 1H, ArH), 7.76 (s, 1H, ArH), 7.85 (s, 1H, ArH), 7.92 (s, 1H, ArH), 8.11 (s, 1H, ArH), 8.17 (s, 3H, ArH), 8.23 (s, 1H, ArH), 8.25 (s, 1H, ArH), $8.42(\mathrm{~s}, 1 \mathrm{H}, \mathrm{ArH}), 8.54\left(\mathrm{~s}, 1 \mathrm{H}\right.$, triazoleH), and $8.58\left(\mathrm{~s}, 1 \mathrm{H}\right.$, triazoleH) ${ }^{13} \mathrm{C}$ $\left\{{ }^{1} \mathrm{H}\right\} \mathrm{NMR}\left(300 \mathrm{MHz}, \mathrm{CDCl}_{3}\right): \delta(\mathrm{ppm}) 15.57,15.73,22.50,22.96,24.51$, $25.35,28.26,29.51,31.21,31.73,33.82,36.26,39.43,39.60,39.76$, $39.93,40.01,40.09,40.19,40.26,40.35,40.43,49.07,63.88,65.25$, $65.41,65.57,70.26,124.30,162.67$, and 173.06.

\subsection{Preparation of Blank and Curcumin-Loaded Micelles}

Blank and curcumin-loaded miktoarm micelles were prepared by a co-solvent evaporation method. ${ }^{[11]}$ Specific weights of the polymer and drug (drug/polymer ratio of 0-40 wt\%) were dissolved in $1.5 \mathrm{~mL}$ of acetone. The solution was added dropwise ( 1 drop/10 s) to $3 \mathrm{~mL}$ of magnetically stirred deionized water. The mixture was stirred in the dark for $24 \mathrm{~h}$ to remove acetone and trigger micelle formation. The mixture was filtered through a $0.45 \mu \mathrm{m}$ PVDF filter to remove the free (non-incorporated) drug. Aliquots of the micellar solutions were tested by dynamic light scattering (DLS) to determine the hydrodynamic diameter $\left(D_{\mathrm{H}}\right)$ and polydispersity index (PDI) of the micelles. Aliquots of the solution were diluted 10 times by acetonitrile and used to determine drug content of the micelles by an HPLC assay.

\subsection{Characterization}

NMR spectra were recorded on a 300 or $400 \mathrm{MHz}$ (as specified) Varian spectrometers at ambient temperatures. The chemical shifts in ppm are reported relative to tetramethylsilane as an internal standard for ${ }^{1} \mathrm{H}$ and ${ }^{13} \mathrm{C}\left\{{ }^{1} \mathrm{H}\right\}$ NMR spectra. Molecular weight and polydispersity index (PDI) were characterized by GPC (Waters Breeze) using THF as the mobile phase. The GPC was equipped with three Waters Styragel HR columns (molecular weight measurement ranges: HR1: $10^{2}-5 \times 10^{3} \mathrm{~g} \mathrm{~mol}^{-1}$, HR2: $5 \times 10^{2}-2 \times 10^{4} \mathrm{~g} \mathrm{~mol}^{-1}$, HR $3: 5 \times 10^{3}-6 \times 10^{5} \mathrm{~g} \mathrm{~mol}^{-1}$ ) and a guard column. The columns were operated at $40^{\circ} \mathrm{C}$ and a mobile phase flow rate of $0.3 \mathrm{~mL} \mathrm{~min}^{-1}$ during analysis. The GPC was also equipped with both ultraviolet (UV 2487) and differential refractive index (RI 2410) detectors. The molecular weight measurements were calibrated relative to poly(styrene) narrow molecular weight standards in THF at $40^{\circ} \mathrm{C}$.

The dynamic light scattering measurements were performed using a Malvern ZetaSizer (Nano-ZS, Malvern Instruments, Worcestershire, UK). The instrument was equipped with a $\mathrm{He}-\mathrm{Ne}$ laser operating at $633 \mathrm{~nm}$ and an avalanche photodiode detector. Samples were filtered through a $0.45 \mu \mathrm{m}$ Millex Millipore PVDF membrane prior to measurements. The mean hydrodynamic diameter, polydispersity index, and scattering intensity of the micelles were determined. Measurements were performed in triplicate at room temperature. Cumulant analysis was applied to obtain the hydrodynamic diameter and polydispersity index of the nanoparticles. The constrained regularized CONTIN method was used to obtain the particle size distribution.

UV-Vis absorption spectra were recorded with an Agilent 8452A photodiode array spectrometer. Steady-state fluorescence spectra were recorded using a Varian Cary Eclipse fluorescence spectrophotometer.

HPLC analysis of curcumin was performed on a Waters chromatography system equipped with Waters $1525 \mu$ binary HPLC pump, Waters 717plus autosampler, Waters Symmetry C18 $5 \mu \mathrm{m}$ and $4.6 \times 150 \mathrm{~mm}$ column, Waters 2487 dual $\lambda$ absorbance detector, and an IBM computer equipped with the Breeze software. The assay was carried out at $25^{\circ} \mathrm{C}$ using a $7: 3 \mathrm{v} / \mathrm{v}$ mixture of acetonitrile- $0.5 \% \mathrm{w} / \mathrm{v}$ citric acid solution adjusted to $\mathrm{pH} 3.0$ by $50 \% \mathrm{w} / \mathrm{v}$ aqueous $\mathrm{KOH}$ solution. The flow rate was $1.2 \mathrm{~mL} \mathrm{~min}^{-1}$. The injection volume was $20 \mu \mathrm{L}$ and the run time was $9 \mathrm{~min}$. Curcumin, monitored by its absorbance at $420 \mathrm{~nm}$, had a retention time $\approx 7.1 \mathrm{~min}$. A calibration curve $\left(r^{2} \geq 0.999\right)$ of curcumin was prepared using standard solutions ranging in concentration from 10 to $50 \mu \mathrm{g} \mathrm{mL}^{-1}$ prepared immediately prior to the assay. To assay curcumin content of different miktoarm micelles, a given volume of aqueous micellar solution was diluted 10 times by acetonitrile to break the micelle structure. The solution was filtered through $0.2 \mu \mathrm{m}$ Millex Millipore nylon filters and assayed by HPLC. Given volume of blank polymeric micelles was treated similarly and used as a control. Curcumin encapsulation efficiency and loading capacity were calculated from:

$$
\begin{aligned}
& \text { CUR encapsulation efficiency (wt } \%) \\
& =\frac{\text { Weight of CUR in the micelles }}{\text { Total weight of CUR used initially }} \times 100
\end{aligned}
$$

$$
\begin{aligned}
& \text { CUR loading capacity (wt } \%) \\
& =\frac{\text { Weight of CUR in micelles }}{\text { Total weight of micelles tested }} \times 100
\end{aligned}
$$

\subsection{UV-Vis Absorption Measurements}

Aliquots of TIF-monoacetylene, $\mathrm{PEG}_{750}-\mathrm{PCL}_{5700^{-}}$TIF, $\mathrm{PEG}_{2000^{-}}$ PCL $_{5700}$-TIF solution in acetone $\left(5 \mathrm{mg} \mathrm{mL}^{-1}\right)$ were diluted in deionized water to reach concentration of $0.005 \mathrm{mg} \mathrm{mL}^{-1}$. Micelles

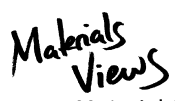

www.MaterialsViews.com 
of PEG ${ }_{750}-\mathrm{PCL}_{5700}$-TIF, $\mathrm{PEG}_{2000}-\mathrm{PCL}_{5700}$-TIF were prepared following the general procedure described above and diluted with deionized water to reach a polymer concentration of $0.08 \mathrm{mg} \mathrm{mL}^{-1}$. The UVvis absorption spectra of aliquots of these solutions were recorded in the range of $200-800 \mathrm{~nm}$.

\subsection{Critical Association Concentration (CAC) of ABC Miktoarm Micelles}

Given volumes of pyrene stock solution in acetone (180 $\mu$ M) were added to a series of $4 \mathrm{~mL}$ vials and the acetone was allowed to evaporate overnight in the dark. Blank miktoarm micelles were prepared following the general procedure described above. Specified volumes of the micellar solutions were added to the vials having pyrene so that polymer concentration varied from 0.025 to $200 \mu \mathrm{g} \mathrm{mL}^{-1}$ while pyrene concentration was kept constant at $6 \mu \mathrm{m}$. The pyrene versus micellar solutions were equilibrated overnight in the dark. Excitation spectra were recorded from 260 to $360 \mathrm{~nm}$ at $\lambda_{\mathrm{em}}=390 \mathrm{~nm}$ (excitation and emission bandpass, $5 \mathrm{~nm}$, respectively). The ratios of the pyrene fluorescence intensities at $\lambda=338$ and $333 \mathrm{~nm}\left(I_{338} / I_{333}\right)$ were calculated and plotted versus polymer concentration. The critical association concentration (CAC) values were determined from the graphs as the intersections of two straight lines (the horizontal line with an almost constant value of the ratio $I_{338} / I_{333}$ and the vertical line with a steady increase in the ratio value).

\subsection{Micelle Colloidal Stability}

Curcumin-loaded micelles were prepared by the co-solvent evaporation method in deionized water and stored at $4{ }^{\circ} \mathrm{C}$ for 45 $\mathrm{d}$. The particle size and polydispersity index of micelles were measured on the freshly prepared sample and on weekly intervals after storage. The micelles were also periodically examined for signs of aggregation/precipitation.

\subsection{Drug Release Studies}

In vitro release of curcumin from miktoarm micelles was studied by the dialysis bag method in phosphate-buffered saline (PBS pH 7.4) containing $1 \% \mathrm{v} / \mathrm{v}$ Tween 80 . Tween 80 was added to maintain perfect sink conditions since curcumin has limited solubility in PBS. Curcumin/miktoarm micellar solutions in deionized water $(2 \mathrm{~mL}$, [CUR] $=0.05-0.10 \mathrm{mg} \mathrm{mL}^{-1}$ ) were introduced in a dialysis tube $(\mathrm{MWCO}=6-8 \mathrm{kDa})$ and dialyzed against $20 \mathrm{~mL}$ of the release medium maintained at $37^{\circ} \mathrm{C}$. At predetermined time intervals, the whole medium was removed and replaced by fresh medium to maintain perfect sink conditions. Curcumin solution at $0.1 \mathrm{mg}$ $\mathrm{mL}^{-1}$ in a solvent mixture of PEG400-water-dimethylacetamide $(45: 40: 15 \mathrm{v} / \mathrm{v})$ was used as a control. ${ }^{[34]}$ Care was taken during the experiments to protect curcumin against light. Ascorbic acid ( $1 \mathrm{mg} \mathrm{mL}^{-1}$ ) was added to the release medium to protect curcumin against degradation. ${ }^{[35]}$ The concentration of the drug in the release samples was determined by HPLC as described above. The cumulative percent of drug released was plotted as a function of dialysis time.

\subsection{Cell Culture}

J774A.1 murine macrophages were cultured in Dulbecco's Modified Eagle Medium (DMEM, Gibco \#11995-073) containing 1\% v/v PenStrep (Gibco \#15140-122) in 10\% v/v fetal bovine serum (FBS, Gibco \#26140-079) media solution. Cells were seeded $24 \mathrm{~h}$ prior to treatment. Treatments were performed in $2 \%$ serum-containing media for nitric oxide, mitochondrial activity and cell count and in serum-free media for uptake, fluorescence and cell imaging. Cell were grown and treated at $37^{\circ} \mathrm{C}$ with $5 \% \mathrm{CO}_{2}$ and $>95 \%$ relative humidity.

\subsection{Fluorescence Measurements}

Fluorescence intensity measurements were carried out using a BMG spectrofluorometer. Macrophages were seeded in a 96 well black plate (Sarstedt) at a density of $1 \times 10^{4}$ cells per well and grown for $24 \mathrm{~h}$ at $37^{\circ} \mathrm{C}$. Cells were treated with fluorescent curcumin micelles $(500 n M-5 \mu \mathrm{M})$ for indicated amounts of time. Cells were immediately washed in PBS pH 5.5 at treatment end-time followed by two additional washes with neutral PBS. Fluorescence was measured using a BMG spectrofluorometer (ex $544 \mathrm{~nm} / \mathrm{em}$ $590 \mathrm{~nm})$

\subsection{Imaging}

To acquire representative images, J774A.1 macrophages were seeded in a chamber slide at a density of $1 \times 10^{4}$ cells per well and grown for $24 \mathrm{~h}$ at $37^{\circ} \mathrm{C}$. They were treated with fluorescent micelles $(5 \mu \mathrm{M}$ TIF) for $1 \mathrm{~h}$, after which cells were fixed with $4 \%$ paraformaldehyde and stained with Hoechst $33342(10 \mu \mathrm{M}$, 10 min, Sigma). The cells were imaged directly using a Leica DMI4000B inverted fluorescence microscope at $63 \times$ magnification. Images were captured with the Leica DFC350FX digital camera using a UV filter (ex 350/em $461 \mathrm{~nm}$ ) and Cy3 filter (ex 543/em $593 \mathrm{~nm}$ ) and analyzed using the Leica Application Suite software for image acquisition.

\subsection{Nitric Oxide Release}

NO release was assessed by measuring nitrite concentration $\left(\mathrm{NO}_{2}{ }^{-}\right)$ in cell media using Griess reagent. J774A.1 macrophages were seeded in 24-well cell culture plate (Sarstedt) at a density of $1 \times 10^{5}$ cells per well in $500 \mu \mathrm{L}$. Cells were pre-treated with curcumin or curcumin micelles for $2 \mathrm{~h}$ before the addition of lipopolysaccharides (LPS) from $E$. coli (L2880). LPS was solubilized in PBS to $1 \mathrm{mg} \mathrm{mL}^{-1}$ and used to activate microglia at an effective concentration of $100 \mathrm{ng} \mathrm{mL}^{-1}$. Twenty hours after the addition of curcumin, triplicate samples of supernatant $(50 \mu \mathrm{L})$ were placed into a 96 well plate (Sarstedt). A standard curve (0-100 $\mu \mathrm{M})$ was generated using sodium nitrite in serum-free cell media. Griess reagent (1\% sulfanilamide, 0.1\% $N$-[1-naphthyl]-ethyleneaminedihydrochloride, 5\% phosphoric acid) (Sigma, G-4410) was added to samples and standards, and incubated at room temperature for $15 \mathrm{~min}$. Absorbance was measured at $540 \mathrm{~nm}$ using a microplate reader (ASYS UVM 340). 


\subsection{Mitochondrial Activity}

J774A.1 macrophages were seeded and treated as above. At treatment end time point, $50 \mu \mathrm{L}$ of 3-(4,5-Dimethylthiazol-2-yl)-2,5diphenyltetrazolium bromide (MTT) solution in PBS $\left(5 \mathrm{mg} \mathrm{mL}^{-1}\right)$ was added to the cells and incubated at $37{ }^{\circ} \mathrm{C}$ with $5 \% \mathrm{CO}_{2}$ and $>95 \%$ relative humidity for $30-35 \mathrm{~min}$. Five hundred microliters of dimethyl sulfoxide (DMSO) was added to lyse the cells and dissolve the formazan crystals. Aliquots of $100 \mu \mathrm{L}$ were collected from each well and transferred in triplicate to a 96 well plate (Sarstedt). Absorbance was measured at $595 \mathrm{~nm}$ using a microplate reader (ASYS UVM 340).

\subsection{Cell Count}

Macrophages were seeded in 12 well plates (Milipore) at a density of $1.5 \times 10^{5}$ cells per well in $1 \mathrm{~mL}$ of media. Cells were pre-treated with curcumin or curcumin micelles $(10 \mu \mathrm{M})$ for $2 \mathrm{~h}$ before addition of LPS (100 ng mL ${ }^{-1}$ ) for a total treatment time of $20 \mathrm{~h}$. At treatment end-time point, cells were mechanically detached from plate bottom, collected, centrifuged and resuspended in $200-300 \mu \mathrm{L}$ of trypan blue solution (1:4 trypan:PBS). Live cells were counted for each condition from two independent experiments $(n=6-8)$.

\section{Results and Discussion}

\subsection{Synthesis of ABC Miktoarm Polymers}

The design of $A B C$ miktoarm star polymers was based on a tri-functional core containing orthogonal functional groups including a protected and a free acetylene. ${ }^{[11]}$ The PEG-azide was covalently attached onto the free acetylene arm of the core using $\mathrm{Cu}(\mathrm{I})$ catalyzed alkyne-azide click chemistry, which was followed by the deprotection of the second acetylene group to afford compound $\mathbf{1}$ (Scheme 1). ${ }^{[36,37]}$ PEG was chosen to provide stability, biocompatibility and aqueous solubility to the micelles. The second acetylene group of compound $\mathbf{1}$ was subsequently used to perform another click reaction with a linker containing an azido focal point and a bromo terminus to yield compound $\mathbf{2}$. Completion of this reaction was easily confirmed by ${ }^{1} \mathrm{H}$ NMR, which showed disappearance of the signal corresponding to the alkyne, and the appearance of a new signal for the triazole proton. The bromo group was then converted to an azide via a simple azidation reaction to yield compound $\mathbf{3}$. The azidation was monitored by a small shift in methylene protons next to azide group in its proton NMR spectrum. Compound $\mathbf{3}$ contains a PEG chain, an azide group to participate in a click reaction for the attachment of propargylated dye, and a hydroxyl group to undergo ring opening polymerization (ROP) with caprolactone to yield the desired hydrophobic segment of the miktoarm polymer (Scheme 1). The choice of polycaprolactone was based on its biodegradability, hydrophobicity, as well as its ability to protect hydrophobic drugs against degradation by solubilizing them in the core of the micelles. Compound 4 with PEG and PCL arms was used to perform a final click reaction with mono-propargylated tetraiodofluorescein dye to yield traceable $A B C$ miktoarm polymers (5, Scheme 1, Figure 1). The excess dye was removed by washing the polymer several times with diethylether.<smiles>C#Cc1cc(CO)cc(-c2cn(CC(C)(C)OCC(C)(C)OC)nn2)c1</smiles>

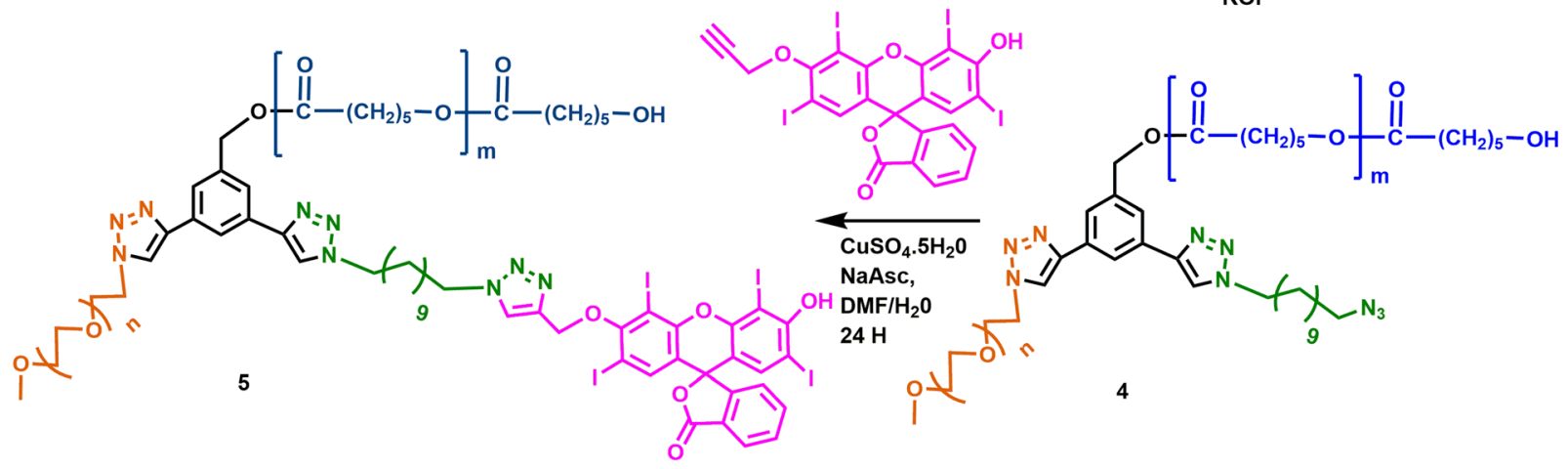

Scheme 1. Synthesis of $A B C$ miktoarm polymers: $A=P E G, B=P C L$, and $C=$ tetraiodofluorescein.

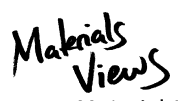

www.MaterialsViews.com 


\section{A) Curcumin}<smiles>COc1cc(/C=C/C(=O)CC(=O)/C=C/c2ccc(O)c(OC)c2)ccc1O</smiles>

\section{B) Polymer structure}

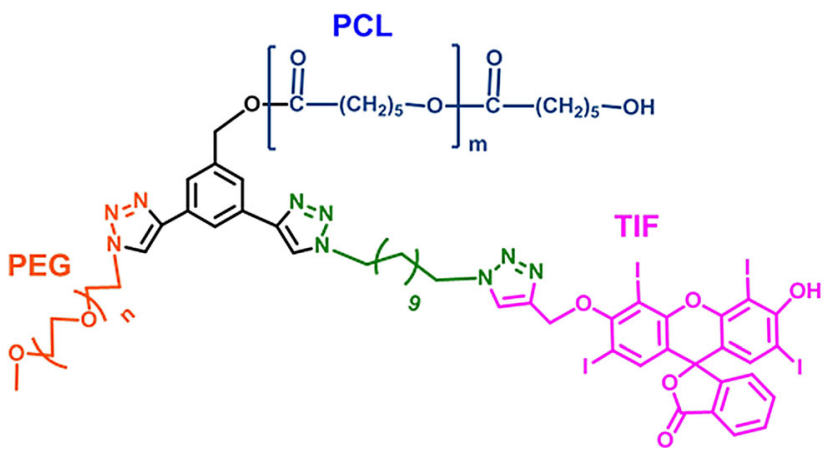

Figure 1. A) Chemical structure of curcumin. B) Structure of $A B C$ type miktoarm star polymer having A: Polyethyleneglycol (PEG), B: Polycaprolactone (PCL), and C: Tetraiodofluorescein (TIF).

Tetraiodofluorescein was chosen as a model fluorescent agent to develop the chemistry since it is cheap and commercially available.

\subsection{UV-Vis Absorption Measurements}

UV-Vis absorption spectra of miktoarm polymers containing TIF dye, either free in solution or self-assembled into micelles were recorded to determine changes in TIF photophysical properties upon conjugation to the miktoarm polymers, and their subsequent self-assembly into micelles. Figure 2A shows that TIF has an absorption band at $531 \mathrm{~nm}$, which shifts to $\approx 547 \mathrm{~nm}$ upon conjugation to miktoarm stars, and to $543 \mathrm{~nm}$ upon micellization. The red shift might be attributed to change in the environment of the dye after conjugation to the polymer or self-assembly into micelles. Song et al., ${ }^{[38]}$ reported a similar red shift in the UV-Vis absorption spectra of fluorescein upon binding to cetyltrimethylammonium bromide micelles, and it was attributed to a more stabilized excited state of fluorescein upon conjugation.

\subsection{Preparation and Characterization of Miktoarm Micelles}

Micelles, with and without curcumin, were prepared in deionized water by the co-solvent evaporation method, which is simple, fast and efficient. It also allows precise control over the final polymer concentration in solution, in contrast to the dialysis method where the polymer concentration cannot be controlled due to water flux through the dialysis membrane. Figure $2 \mathrm{~B}$ shows that $\mathrm{PEG}_{750}$ PCL $_{5700}$-TIF miktoarm polymer forms micelles with unimodal size distribution and a hydrodynamic diameter of $\approx 116 \mathrm{~nm}$. The size and its distribution remained unaffected by the incorporation of $\approx 4$ wt\% curcumin (Figure $2 \mathrm{C}$ ). In addition to the traceable polymers with covalently linked TIF, self-assembly behavior of polymers without any TIF moiety and containing azide groups instead (Table 1) was also investigated. There was no significant difference in micelle size between the traceable polymers and those having azide groups (Table 2). The size of the micelles from polymers containing $\mathrm{PEG}_{2000}$ was generally smaller than those with $\mathrm{PEG}_{750}$ (Table 2). It is an intriguing observation since it has been reported that bigger micelles are formed upon increasing the chain length of PEG or PCL. ${ }^{[39,40]}$ Curcumin-loaded micelles of these polymers were prepared at an initial curcumin versus polymer weight ratio of $10 \%$. The size of curcumin-loaded micelles was larger than that of the empty micelles which suggested curcumin incorporation into the micelle core (Table 2). ${ }^{[11]}$ Curcumin loading in these micelles was $\approx 3-5 \mathrm{wt} \%$ with an encapsulation efficiency of $27-55 w t \%$ which is comparable to other miktoarm polymer micelles with similar drug loading capacities. ${ }^{[12,41]}$ Polymers with $\mathrm{PEG}_{2000}$ and $\mathrm{PCL}_{21000}$ precipitated in aqueous solution and did not form micelles. This is most probably because the chain length of PEG is not big enough to stabilize a micelle with high molecular weight of PCL. ${ }^{[12]}$

\subsection{Micelle Critical Association Concentration (CAC)}

The CAC is a crucial parameter of polymeric micelles that characterizes their stability upon dilution. Low CAC values help prevent premature drug release upon extensive dilution following in vivo administration. ${ }^{[4]}$ CAC of $\mathrm{PEG}_{750}-\mathrm{PCL}_{5700}-\mathrm{N}_{3}$ and $\mathrm{PEG}_{750}-\mathrm{PCL}_{5700}$-TIF was measured using pyrene as a fluorescent probe. This method is widely used in the determination of polymeric micelle CAC due to its ease in application, versatility and reliability. ${ }^{[42,43]}$ Excitation spectra of aqueous polymer solutions containing pyrene $(6 \mu \mathrm{M})$ and different polymer concentrations were recorded from 260 to $360 \mathrm{~nm}$ at $\lambda_{\mathrm{em}}=390 \mathrm{~nm}$. Pyrene has unique photophysical properties as it undergoes a red shift in the excitation spectrum and a blue shift in the emission spectrum, when it passes from hydrophilic to hydrophobic media. ${ }^{[44]}$ Semilogarithmic plots of the $I_{338} /$ $I_{333}$ ratios versus the concentration of $\mathrm{PEG}_{750}-\mathrm{PCL}_{5700}-\mathrm{N}_{3}$ and $\mathrm{PEG}_{750}-\mathrm{PCL}_{5700}$-TIF miktoarm polymers are shown in Figure 2D. The $I_{338} / I_{333}$ ratio remained almost constant at low polymer concentration and increased sharply when the polymer concentration reached its CAC. The CAC values for $\mathrm{PEG}_{750}-\mathrm{PCL}_{5700}-\mathrm{N}_{3}$ and $\mathrm{PEG}_{750}-\mathrm{PCL}_{5700}$-TIF miktoarm 

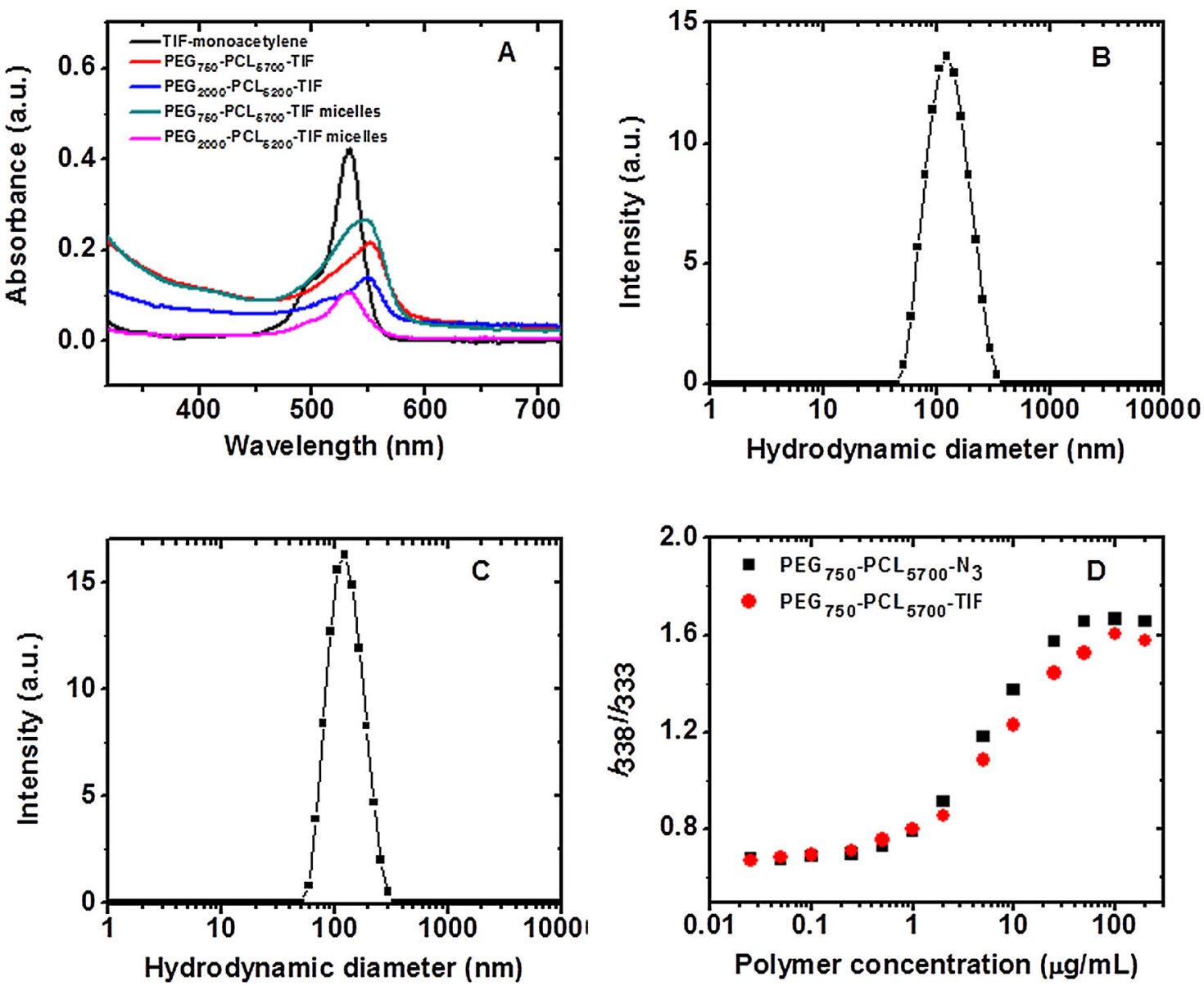

Figure 2. A) UV-Vis absorption spectra of TIF-monoacetylene dye, $\mathrm{PEG}_{750}-\mathrm{PCL}_{5700}-\mathrm{TIF}$ polymer solution and micelles, $\mathrm{PEG}_{2000}-\mathrm{PCL}_{5200}-\mathrm{TIF}$

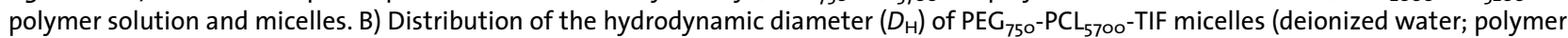
concentration, $\left.0.5 \mathrm{gL}^{-1} ; \theta, 90^{\circ}\right)$. C) Distribution of the hydrodynamic diameter $\left(D_{\mathrm{H}}\right)$ of CUR/PEG ${ }_{750}-\mathrm{PCL}_{5700}-\mathrm{TIF}$ micelles (deionized water; polymer concentration, $0.5 \mathrm{~g} \mathrm{~L}^{-1} ; \theta, 90^{\circ}$; curcumin loading, $\left.4 \mathrm{wt} \%\right)$. D) Plots of intensity ratio $\left(I_{338} / I_{333}\right)$ of pyrene excitation spectra $\left(\lambda_{\mathrm{em}}=390 \mathrm{~nm}\right)$ versus concentration of different $\mathrm{PEG}_{750}-\mathrm{PCL}_{5700}-\mathrm{N}_{3}$ and $\mathrm{PEG}_{750}-\mathrm{PCL}_{5700}$ TIF miktoarm polymers in water.

polymers were 0.42 and $0.43 \mu \mathrm{g} \mathrm{mL}^{-1}$, respectively. This confirms that the presence of TIF dye did not affect the selfassembly behavior of these polymers.

\subsection{Effect of Curcumin versus Polymer Weight Feed Ratio on Micelle Size and Drug Loading}

In order to achieve maximum curcumin loading while minimizing the concentration of miktoarm polymers,

Table 1. GPC analysis of $A B C$ miktoarm polymers.

\begin{tabular}{lcc} 
Polymer & $\overline{\boldsymbol{M}}_{\mathbf{n}}{ }^{\mathbf{a}}[\mathbf{k D a}]$ & PDI $^{\mathbf{b})}$ \\
\hline $\mathrm{PEG}_{750}-\mathrm{PCL}_{5700}-\mathrm{N}_{3}(\mathbf{4 a})$ & 6.85 & 1.30 \\
$\mathrm{PEG}_{2000}-\mathrm{PCL}_{5200}-\mathrm{N}_{3}(\mathbf{4 b})$ & 7.60 & 1.34 \\
$\mathrm{PEG}_{2000}-\mathrm{PCL}_{21000}-\mathrm{N}_{3}(\mathbf{4 c})$ & 22.72 & 1.44
\end{tabular}

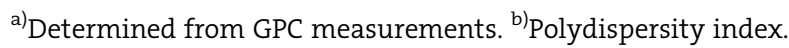

micelles were prepared at different curcumin versus polymer weight ratios (varying from 0 to $40 \%$ ). Incorporation of curcumin into the micelles did not have a noticeable effect on their size at curcumin to polymer ratios of up to $20 \mathrm{wt} \%$, after which there was a significant change in size (Figure 3A). For instance, the micelle hydrodynamic diameter increased from $116.3 \pm 1.5$ to $126 \pm 1.2 \mathrm{~nm}$ as the curcumin versus polymer ratio was increased from 0 to $40 \%$. Drug incorporation into micelle core usually results in increased size due to core expansion to accommodate the guest drug molecules. ${ }^{[1,45]}$ The level of curcumin loading was found to increase proportionally to the curcumin versus polymer weight ratio. For example, drug loading increased from 0 to $\approx 12 \mathrm{wt} \%$ when the curcumin versus polymer ratio was increased from 0 to $20 \mathrm{wt} \%$, after which it remained unchanged (Figure 3A). As the curcumin versus polymer feed ratio increases, more drug molecules get incorporated into micelle core until the maximum loading capacity is achieved. The maximum

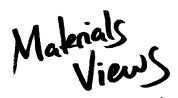

www.MaterialsViews.com 


\begin{tabular}{|c|c|c|c|c|c|}
\hline \multirow[b]{2}{*}{ Polymer } & \multicolumn{2}{|c|}{ Micelle diameter ${ }^{\mathrm{a})}$} & \multirow[b]{2}{*}{$\% \mathrm{DI}^{\mathrm{b})}$} & \multirow[b]{2}{*}{$\% \mathrm{LE}^{\mathrm{c}}$} & \multirow{2}{*}{$\begin{array}{c}\text { CAC }^{\mathrm{d})} \\
{\left[\mu \mathrm{g} \mathrm{mL}^{-1}\right]}\end{array}$} \\
\hline & Blank micelles & CUR micelles & & & \\
\hline $\mathrm{PEG}_{750}-\mathrm{PCL}_{5700}-\mathrm{N}_{3}(\mathbf{4 a})$ & $113.47 \pm 1.7$ & $149.2 \pm 1.45$ & $2.70 \pm 0.24$ & $27.0 \pm 2.4$ & 0.42 \\
\hline $\mathrm{PEG}_{750}-\mathrm{PCL}_{5700}$-TIF (5a) & $116.3 \pm 1.5$ & $115.3 \pm 2.0$ & $3.92 \pm 0.02$ & $39.2 \pm 0.2$ & 0.43 \\
\hline $\mathrm{PEG}_{2000}-\mathrm{PCL}_{5200}-\mathrm{N}_{3}(\mathbf{4 b})$ & $79.3 \pm 3.7$ & $95.0 \pm 0.65$ & $4.52 \pm 0.1$ & $45.2 \pm 1.0$ & - \\
\hline $\mathrm{PEG}_{2000}-\mathrm{PCL}_{5200}$-TIF $(\mathbf{5 b})$ & $71.0 \pm 2.0$ & $170.2 \pm 1.45$ & $5.59 \pm 0.04$ & $55.9 \pm 0.4$ & - \\
\hline $\mathrm{PEG}_{2000}-\mathrm{PCL}_{21000}-\mathrm{N}_{3}(\mathbf{4 c})$ & PPT & PPT & - & - & - \\
\hline
\end{tabular}

${ }^{a}$ Hydrodynamic diameter (nm), mean of three measurements $\pm \mathrm{SD}$; ${ }^{\mathrm{b})}$ Percent drug loading = weight of CUR in micelles $\times 100 /$ weight of micelles tested, mean of three measurements $\pm \mathrm{SD} ;{ }^{\mathrm{C})}$ Percent loading efficiency $=$ weight of CUR in micelles $\times 100 /$ weight of CUR used in micelle preparation; ${ }^{\text {d) }}$ Critical association concentration of micelles in water; PPT: precipitated.

drug loading of a given polymeric micelle formulation is dependent on many factors, the most important of which is compatibility between the drug and the core forming block of the copolymer. A similar trend has been observed for other polymeric micelle formulations. ${ }^{[46-49]}$ The curcumin encapsulation efficiency was in the range of $25-60 \%$ and was highest for curcumin versus polymer ratio of $20 \mathrm{wt} \%$. No drug precipitation was observed for micellar solutions with curcumin versus polymer feed weight ratio of $20 \mathrm{wt} \%$ after storage at $4{ }^{\circ} \mathrm{C}$ for $45 \mathrm{~d}$. Furthermore, the micelle size did not change either during this period, confirming micelle stability.

\subsection{Solubilization of Curcumin by $\mathrm{PEG}_{750}-\mathrm{PCL}_{5700^{-}}$ TIF Miktoarm Micelles}

Curcumin has a very limited aqueous solubility of $11 \mathrm{ng}$ $\mathrm{mL}^{-1}$ at $\mathrm{pH} 5.0$ due to its hydrophobic nature (Figure $\left.1 \mathrm{~A}\right) .^{[25]}$ Low drug solubility in water usually results in poor bioavailability and drug efficacy. ${ }^{[50]}$ The potential of $A B C$ miktoarm micelles to enhance curcumin aqueous solubility was subsequently studied, and it was found to be dependent on the curcumin versus polymer ratio (Figure $3 \mathrm{~A}$ ) and on the polymer concentration. Thus, at polymer concentration of $0.5 \mathrm{mg} \mathrm{mL}^{-1}$ curcumin aqueous solubility increased from $19.6 \pm 0.12$ to $62.2 \pm 0.1 \mu \mathrm{g} \mathrm{mL}^{-1}$ as the curcumin versus polymer ratio was increased from 10 to $40 \mathrm{wt} \%$. The solubility dramatically increased to $279.4 \pm 2.1 \mu \mathrm{g} \mathrm{mL}^{-1}(0.75 \mathrm{mM})$ at $\mathrm{PEG}_{750}-\mathrm{PCL}_{5700}$-TIF polymer concentration of $2 \mathrm{mg} \mathrm{mL}^{-1}$ and curcumin versus polymer initial ratio of $25 \mathrm{wt} \%$. This corresponds to a 25000 fold increase in curcumin aqueous solubility.

\subsection{In Vitro Curcumin Release from ABC Miktoarm Micelles}

The in vitro release of curcumin from $A B C$ miktoarm polymer based micelles was evaluated by the dialysis bag
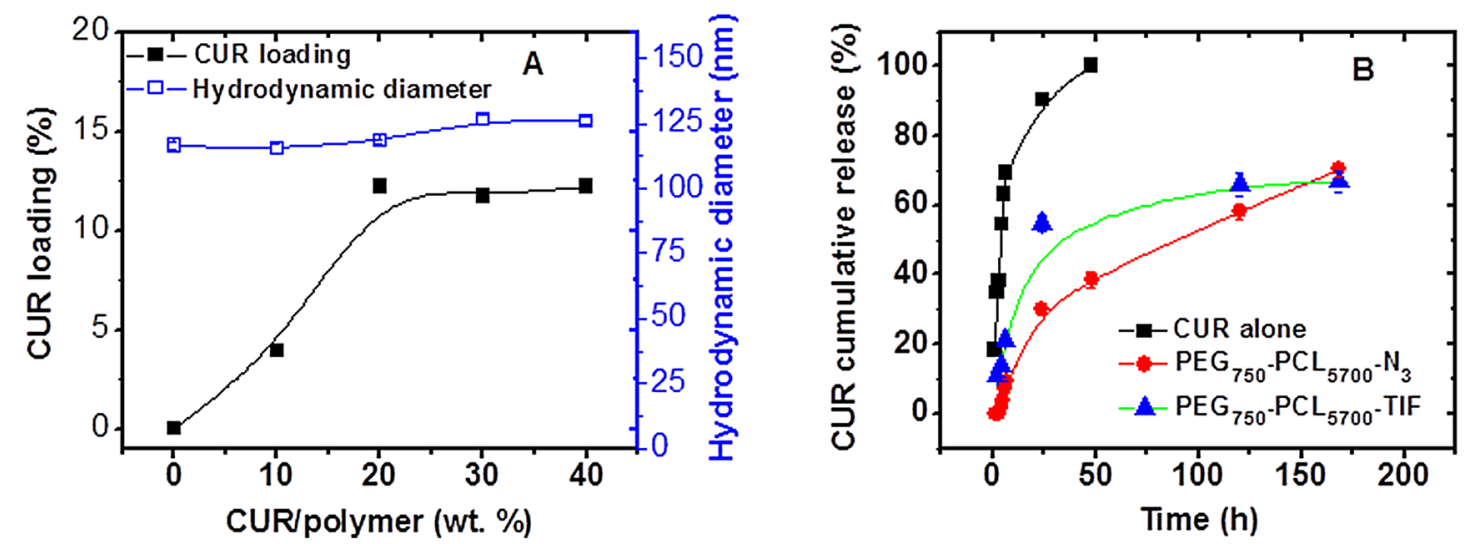

Figure 3. A) Effect of drug versus polymer weight feed ratio on drug loading capacity and micelle hydrodynamic diameter of curcumin/ $\mathrm{PEG}_{750}-\mathrm{PCL}_{5700}$-TIF micelles, prepared in deionized water at polymer concentration of $0.5 \mathrm{mg} \mathrm{mL}^{-1}$. B) Cumulative percent curcumin released from $\mathrm{PEG}_{750}-\mathrm{PCL}_{5700}-\mathrm{N}_{3}$ and $\mathrm{PEG}_{750}-\mathrm{PCL}_{5700}-\mathrm{TIF}$ micelles in $\mathrm{PBS} \mathrm{pH} 7.4$ having $1 \% \mathrm{v} / \mathrm{v}$ Tween 80 at $37^{\circ} \mathrm{C}$. 
method, using a release medium of PBS at $\mathrm{pH} 7.4$ in the presence of $1 \% \mathrm{v} / \mathrm{v}$ Tween ${ }^{\circledR} 80$. The latter is a low molecular weight non-ionic surfactant that can be added to release media to maintain sink conditions for hydrophobic drugs. ${ }^{[26,51]}$ Curcumin solubility in the release medium was $240.8 \mu \mathrm{g} \mathrm{mL}^{-1}$, and it confirmed the maintenance of sink conditions with a given release volume of $20 \mathrm{~mL}$ and the curcumin amount in the micelles at 100-200 $\mu \mathrm{g}$. Free curcumin rapidly diffused through the dialysis membrane, and almost complete release was observed after $24 \mathrm{~h}$
(Figure 3B). In contrast, curcumin encapsulation into the miktoarm micelles significantly slowed down its release. After $7 \mathrm{~d}$ of dialysis time, only $\approx 70$ and $66 \%$ of curcumin was released from $\mathrm{PEG}_{750}-\mathrm{PCL}_{5700}-\mathrm{N}_{3}$ and $\mathrm{PEG}_{750}-\mathrm{PCL}_{5700}-\mathrm{TIF}$ based micelles, respectively. The curcumin release pattern was similar for both micellar systems and was not affected by the presence of the TIF dye. These results suggest that miktoarm micelles provide a sustained curcumin release, which is favorable for reduced frequency of drug administration and better patient compliance.
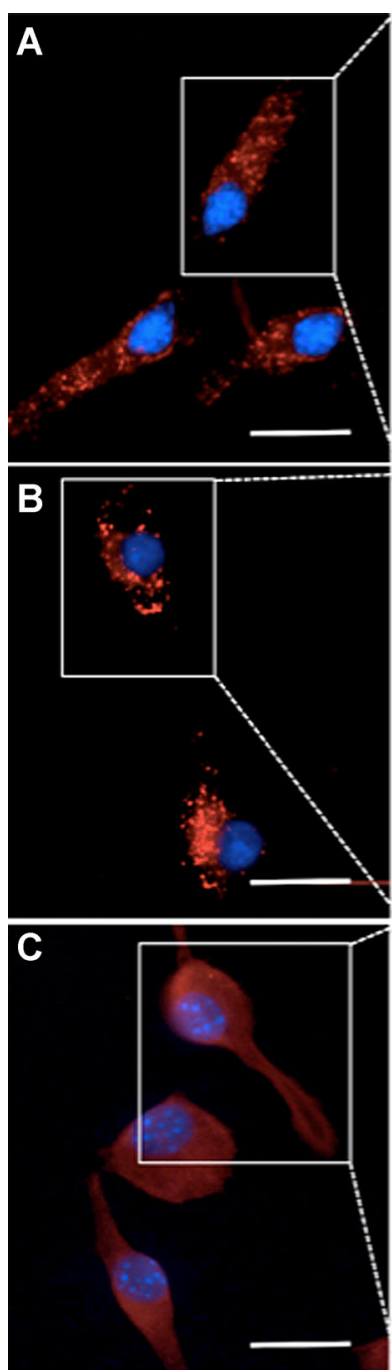
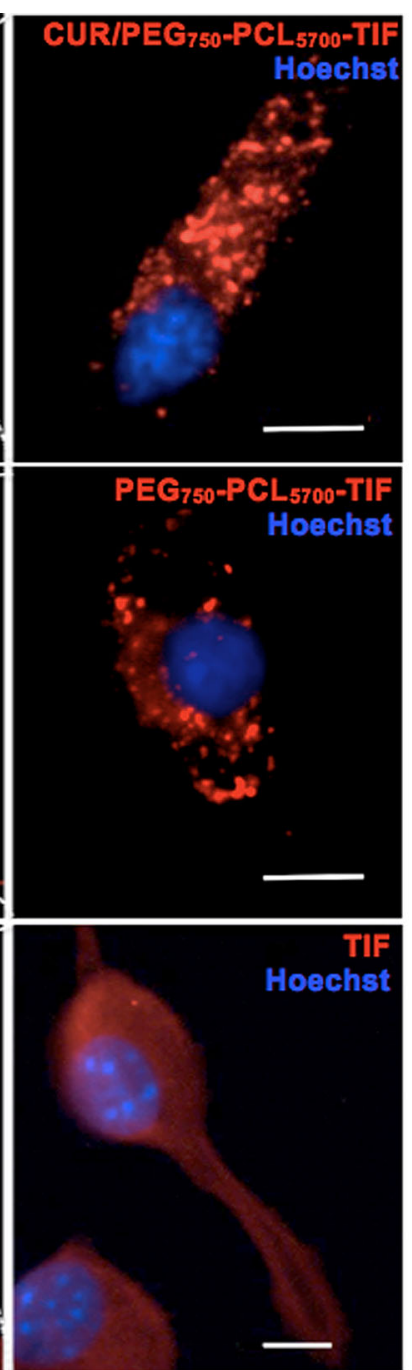
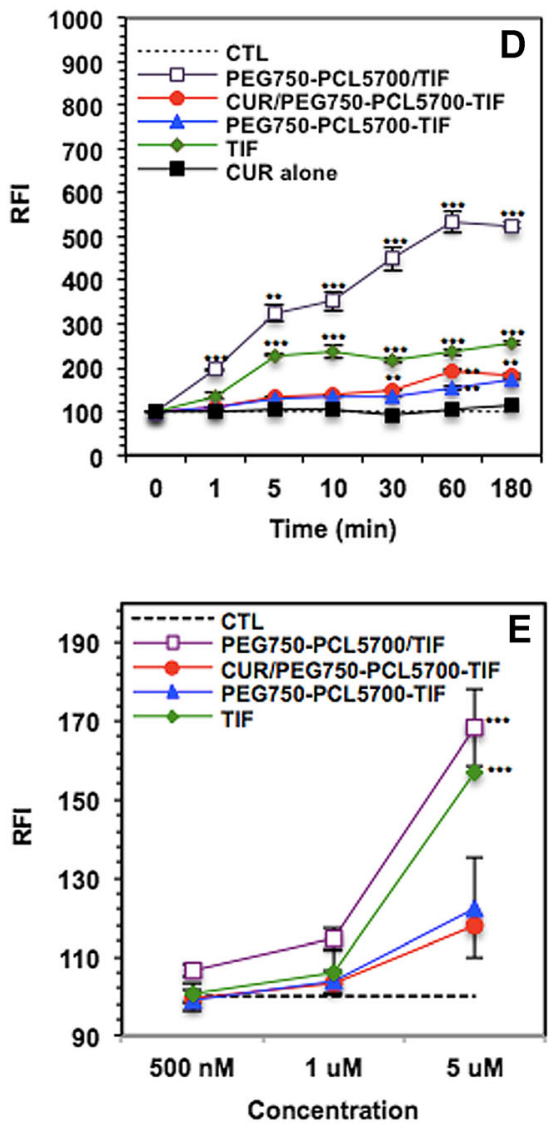

Figure 4. J774A.1 macrophages were treated with A) CUR/PEG ${ }_{750}-\mathrm{PCL}_{5700}-\mathrm{TIF}$ micelles, B) $\mathrm{PEG}_{750}-\mathrm{PCL}_{5700}$-TIF micelles, both with covalently attached TIF, or C) TIF control at a concentration of $5 \mu \mathrm{M}$ for $1 \mathrm{~h}$ in serum free media. Cells were fixed and nuclei were stained with Hoechst 33342 (10 $\mu \mathrm{M}, 10 \mathrm{~min})$. Fluorescent micrographs were obtained using an inverted fluorescence microscope (Cy3 543 nm/593 nm) and images processed using ImageJ. Scale bars represent 20 and $10 \mu \mathrm{m}$ for inset. D) Macrophages were treated with micellar constructs or control, where $\mathrm{PEG}_{750}-\mathrm{PCL}_{5700} / \mathrm{TIF}$ has physically encapsulated TIF while $\mathrm{PEG}_{750}-\mathrm{PCL}_{5700}$-TIF has covalently attached TIF. Cells were treated with $(5 \mu \mathrm{M})$ of constructs for 1 to $180 \mathrm{~min}$ in serum free media. At treatment end-time point cells were washed and RFI was measured using a spectrofluorometer $(544 \mathrm{~nm} / 590 \mathrm{~nm})$. E) Similarly, RFI was measured for cells treated for $1 \mathrm{~h}$ with constructs $(500 \mathrm{nM}-5 \mu \mathrm{M})$ and uptake was observed in a dose-dependent fashion. The data is presented as mean $\pm \operatorname{SEM}(n=4)$. Statistically significant differences from control were calculated using a t-test followed by Bonferroni correction for multiple comparisons and are indicated by ${ }^{*}(p<0.05)$, ${ }^{* *}(p<0.01)$, and ${ }_{* * *}(p<0.001)$

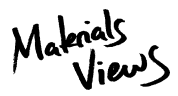

www.MaterialsViews.com 


\subsection{Biological Studies}

Biological experiments were carried out in murine macrophages, selected because these cells are a first line of response to foreign stimuli and are known to internalize particulate matter both in vitro and in vivo. J774A.1 macrophages were treated with fluorescent micelles loaded with curcumin ( $5 \mu \mathrm{M}$; Figure $4 \mathrm{~A}$ ) or micelles without the drug in serum-free media for up to $3 \mathrm{~h}$ (Figure 4B), and relative fluorescence intensity (RFI) was measured at various times (0-180 min; Figure 4D). The results suggest rapid internalization of micelles since a strong fluorescent signal was detected within $5 \mathrm{~min}$, reaching maximum by $60 \mathrm{~min}$. No further changes in fluorescence intensity were observed after $3 \mathrm{~h}$. In addition, micelles (0-5 $\mu \mathrm{M})$ were internalized in a dose-dependent manner (Figure 4E). Photomicrographs were acquired using a fluorescence microscope with optimal setting for Сy3 543/593. The images were taken after 1 -h treatment in J774A.1 macrophages seeded on chamber slides. Nuclei were labeled with Hoechst 33342 (10 $\mathrm{min}, 10 \mu \mathrm{M}$ ), and $\mathrm{PEG}_{750}-\mathrm{PCL}_{5700}$-TIF and CUR/PEG $750-$ PCL $_{5700}$-TIF micelles were clearly seen as distinct puncta (most likely associated with lysosomes). Micelles that are not targeted to certain organelle are
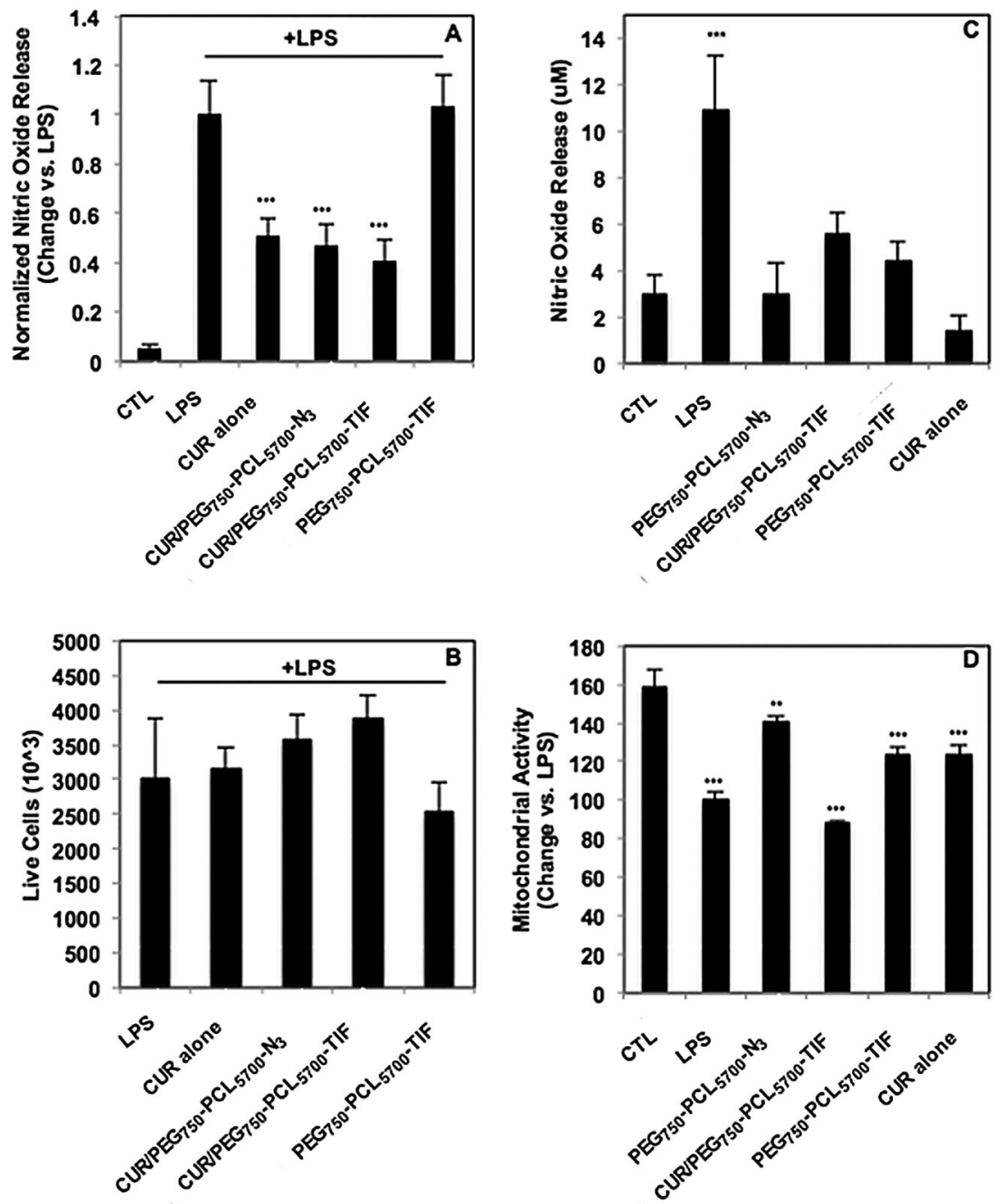

Figure 5. J774A.1 macrophages were pre-treated with curcumin $(1-20 \mu \mathrm{M})$ for $2 \mathrm{~h}$ followed by LPS (100 $\left.\mathrm{ng} \mathrm{mL} \mathrm{L}^{-1}, 18 \mathrm{~h}\right)$ for a total treatment time of $20 \mathrm{~h}$. Nitric oxide release was measured using Griess reagent. $\mathrm{C}_{50}$ for nitric oxide inhibition by curcumin was calculated to be $\approx 11 \mu \mathrm{M}$ (Figure SII, Supporting information). A) Macrophages were similarly treated with curcumin or curcumin micelles (10 $\mu \mathrm{M}$ ) and nitrite release was normalized to cell count. B) Live cells were treated as in A), collected at treatment end-time point, and counted under a bright-light microscope using trypan blue. C) Curcumin alone or curcumin micelles without LPS do not significantly induce nitric oxide production. D) All treatments significantly inhibit mitochondrial activity as compared to untreated control, but do not affect cell survival. The data is presented as mean \pm SEM from at least two independent experiments $(n=6-8)$. Statistically significant differences from control were calculated using a $t$-test followed by Bonferroni correction for multiple comparisons and are indicated by ${ }^{* *}(p<0.01)$ and ${ }^{* * *}(p<0.001)$. Abbreviations: $\mathrm{CTL}=$ untreated control; $\mathrm{CUR}=$ curcumin, $\mathrm{LPS}=$ lipopolysaccharides. 
commonly found in lysosomes after $60 \mathrm{~min} \cdot{ }^{[52-54]}$ Micelles are destined for degradation as revealed by gradual decline of RFI after 60 min of treatment. TIF alone (Figure 4C), as well as TIF physically incorporated into micelles (Figure SI, Supporting Information) disperse throughout the cell, suggesting superior traceability of micelles with a covalently bound fluorophore. Overall, drug-loaded micelles retain strong fluorescence intensity and are easily visualized in vitro, making them useful traceable drug-delivery systems.

The therapeutic effect of curcumin-loaded micelles was studied in macrophages since these innate immuneresponse cells mediate the inflammatory response by releasing pro-inflammatory cytokines and small molecules such as nitric oxide. ${ }^{[30]}$ J774A.1 macrophages were pretreated with lipopolysaccharides (LPS) from E. coli (100 ng $\mathrm{mL}^{-1}$ ) for $2 \mathrm{~h}$ before treatment with micelles or controls for $18 \mathrm{~h}$. At treatment end-time point, nitric oxide (NO) was measured in the cellular supernatant. LPS-induced NO release was inhibited by curcumin alone in a dosedependent manner with an $\mathrm{IC}_{50}$ of $10 \mu \mathrm{m}$ without affecting mitochondrial metabolic activity (Figure SII, Supporting Information). Micelles (10 $\mu$ c curcumin) were tested for curcumin effectiveness to reduce NO release. NO release was normalized to cell number as determined by performing a live cell count using trypan blue (Figure $5 \mathrm{~B}$ ). The results indicate that $\mathrm{CUR} / \mathrm{PEG}_{750}-\mathrm{PCL}_{5700^{-T I F}}$ and $\mathrm{CUR} / \mathrm{PEG}_{750^{-}}$ $\mathrm{PCL}_{5700}-\mathrm{N}_{3}$ micelles significantly inhibit NO release from LPS activated macrophages while micelles without loaded curcumin $\left(\mathrm{PEG}_{750}-\mathrm{PCL}_{5700}-\mathrm{TIF}\right)$ do not (Figure $\left.5 \mathrm{~A}\right)$. This suggests that curcumin was released from micelles and exerted an inhibitory effect comparable to free curcumin. In the absence of LPS treatment, micelles did not trigger the release of NO (Figure 5C). None of the treatments fully recovered mitochondrial metabolic activity in LPS-stimulated macrophages (Figure 5D). Collectively, the results presented in these studies clearly suggest that $A B C$ starpolymer based micelles provide an interesting platform in developing nanocarriers, which can be tracked, and can deliver hydrophobic drugs retaining their biological activity.

\section{Conclusion}

Nanocarriers that can integrate multiple functions including enhanced solubilization and tracing their fate during the delivery of hydrophobic pharmaceutical agents, provide exciting opportunities for effective therapeutic interventions, and miktoarm star polymers have offered considerable potential in this regard. We have developed a methodology to synthetically articulate the location of different functional units into these branched structures. $A B C$ type miktoarm stars containing covalently linked tetraiodofluorescein, polyethylene glycol, and polycaprolactone self-assemble into micelles that incorporate an imaging probe at the core. We have demonstrated that these inherently fluorescent nanocarriers significantly increased the solubility, loading, and sustained release characteristics of hydrophobic drugs such as curcumin, and more importantly help trace these micelles in live cells. Our results provide a general platform on which one could enable the construction of a variety of traceable nanocarriers using simple and highly efficient chemistry, and expand the scope of pharmacological agents with poor aqueous solubility and chemical instability in biological media.

Acknowledgements: G.M.S. and R.R. contributed equally to this work. R.R. gratefully acknowledges financial support from CONACyT CB-2011-01-167356 project and the sabbatical leave grant from PASPA (DGAPA-UNAM), which allowed the realization of the present investigation. A.K. and D.M. thank Natural Sciences and Engineering Research Council (Canada), Canadian Institutes of Health Research (D.M.), and Center for Self-assembled Chemical Structures (Quebec, Canada, (A.K.)) for financial support.

Received: March 6, 2014; Revised: April 16, 2014; Published online: June 6, 2014; DOI: 10.1002/mabi.201400123

Keywords: curcumin; inherently fluorescent stars; Miktoarm polymers; micelles; nanoparticles; traceable delivery

[1] V. Torchilin, in Multifunctional Pharmaceutical Nanocarriers (Ed., V. Torchilin), Springer, New York 2008, p 1.

[2] V. P. Torchilin, Adv. Drug Delivery Rev. 2006, 58, 1532.

[3] L. Jabr-Milane, L. van Vlerken, H. Devalapally, D. Shenoy, S. Komareddy, M. Bhavsar, M. Amiji, J. Controlled Release 2008, $130,121$.

[4] X.-B. Xiong, A. Falamarzian, S. M. Garg, A. Lavasanifar, J. Controlled Release 2011, 155, 248.

[5] Macromolecular Drug Delivery, Methods and Protocols, Vol. 480 (Ed: M. Belting), Humana Press, New York, USA 2009.

[6] J. Nicolas, S. Mura, D. Brambilla, N. Mackiewicz, P. Couvreur, Chem. Soc. Rev. 2013, 42, 1147.

[7] N. Nasongkla, E. Bey, J. Ren, H. Ai, C. Khemtong, J. S. Guthi, S.-F. Chin, A. D. Sherry, D. A. Boothman, J. Gao, Nano Lett. 2006, 6, 2427.

[8] X. Zhang, Y. Dong, X. Zeng, X. Liang, X. Li, W. Tao, H. Chen, Y. Jiang, L. Mei, S.-S. Feng, Biomaterials 2014, 35, 1932.

[9] G. M. Soliman, A. Sharma, D. Maysinger, A. Kakkar, Chem. Commun. 2011, 47, 9572.

[10] K. Khanna, S. Varshney, A. Kakkar, Polym. Chem. 2010, 1 , 1171.

[11] A. Sharma, G. M. Soliman, N. Al-Hajaj, R. Sharma, D. Maysinger, A. Kakkar, Biomacromolecules 2012, 13, 239.

[12] G. M. Soliman, R. Sharma, A. O. Choi, S. K. Varshney, F. M. Winnik, A. K. Kakkar, D. Maysinger, Biomaterials 2010, 31, 8382.

[13] M. A. Tomren, M. Másson, T. Loftsson, H. H. Tønnesen, Int. J. Pharm. 2007, 338, 27.

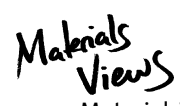

www.MaterialsViews.com 
[14] H. P. T. Ammon, M. A. Wahl, Planta Med. 1991, 57, 1.

[15] X. Fan, C. Zhang, D-b. Liu, J. Yan, H-p. Liang, Curr. Pharm. Des. 2013, 19, 2011.

[16] S. M. Plummer, K. A. Holloway, M. M. Manson, R. J. L. Munks, A. Kaptein, S. Farrow, L. Howells, Oncogene 1999, 18, 6013.

[17] I. Brouet, H. Ohshima, Biochem. Biophys. Res. Commun. 1995, 206, 533

[18] G. R. B. Irving, L. M. Howells, S. Sale, I. Kralj-Hans, W. S. Atkin, S. K. Clark, R. G. Britton, D. J. L. Jones, E. N. Scott, D. P. Berry, D. Hemingway, A. S. Miller, K. Brown, A. J. Gescher, W. P. Steward, Cancer Prev. Res. 2013, 6, 119.

[19] S. Muglikar, K. C. Patil, S. Shivswami, R. Hegde, Oral Health Prev. Dent. 2013, 11, 81.

[20] B. Chandran, A. Goel, Phytother. Res. 2012, 26, 1719.

[21] R. E. Carroll, R. V. Benya, D. K. Turgeon, S. Vareed, M. Neuman, L. Rodriguez, M. Kakarala, P. M. Carpenter, C. McLaren, F. L. Meyskens, D. E. Brenner, Cancer Prev. Res. 2011, 4, 354.

[22] The Molecular Targets and Therapeutic Uses of Curcumin in Health and Disease, Advances in Experimental Medicine and Biology Series, Vol. 595 (Eds: B. Aggarwal, Y.-J. Surh, S. Shishodia), Springer, New York, USA 2007.

[23] C. Lao, M. Ruffin, D. Normolle, D. Heath, S. Murray, J. Bailey, M. Boggs, J. Crowell, C. Rock, D. Brenner, BMC Complement. Altern. Med. 2006, 6, 10.

[24] P. Anand, A. B. Kunnumakkara, R. A. Newman, B. B. Aggarwal, Mol. Pharm. 2007, 4, 807.

[25] H. H. Tønnesen, M. Másson, T. Loftsson, Int. J. Pharm. 2002, $244,127$.

[26] C. Gong, O. Wu, Y. Wang, D. Zhang, F. Luo, X. Zhao, Y. Wei, Z. Oian, Biomaterials 2013, 34, 6377.

[27] Z. S. Ma, A. Haddadi, O. Molavi, A. Lavasanifar, R. Lai, J. Samuel, J. Biomed. Mater. Res. A 2008, 86A, 300.

[28] C. Mohanty, S. Acharya, A. K. Mohanty, F. Dilnawaz, S. K. Sahoo, Nanomedicine 2010, 5, 433.

[29] M. Sun, X. Su, B. Ding, X. He, X. Liu, A. Yu, H. Lou, G. Zhai, Nanomedicine 2012, 7, 1085.

[30] M. A. Dobrovolskaia, S. N. Vogel, Microbes Infect. 2002, 4, 903.

[31] B. Beutler, E. T. Rietschel, Nat. Rev. Immunol. 2003, 3, 169.
[32] S. Derbré, G. Roué, E. Poupon, S. A. Susin, R. Hocquemiller, ChemBioChem 2005, 6, 979.

[33] L. Chen, T.-S. Hu, J. Zhu, H. Wu, Z.-J. Yao, Synlett 2006, 1225.

[34] Z. Song, R. Feng, M. Sun, C. Guo, Y. Gao, L. Li, G. Zhai, J. Colloid Interface Sci. 2011, 354, 116

[35] S. Oetari, M. Sudibyo, J. N. M. Commandeur, R. Samhoedi, N. P. E. Vermeulen, Biochem. Pharmacol. 1996, 51, 39.

[36] H. C. Kolb, M. G. Finn, K. B. Sharpless, Angew. Chem. Int. Ed. 2001, 40, 2004.

[37] G. Franc, A. K. Kakkar, Chem. Soc. Rev. 2010, 39, 1536.

[38] A. Song, J. Zhang, M. Zhang, T. Shen, J. A. Tang, Colloids Surf. A 2000, 167, 253.

[39] G. M. Soliman, F. M. Winnik, Int. J. Pharm. 2008, 356, 248.

[40] A. Richter, C. Olbrich, M. Krause, T. Kissel, Int. J. Pharm. 2010, 389, 244

[41] H. Li, M. Diao, S. Zhang, K. Wang, C. Xue, J. Nanosci. Nanotechnol. 2009, 9, 4805.

[42] G. Riess, Prog. Polym. Sci. 2003, 28, 1107.

[43] X. Huang, X. Jiang, O. Yang, Y. Chu, G. Zhang, B. Yang, R. Zhuo, J. Mater. Chem. B 2013, 1, 1860.

[44] K. Lee, S.-C. Shin, I. Oh, Arch. Pharm. Res. 2003, 26, 653.

[45] F. Nederberg, E. Appel, J. P. K. Tan, S. H. Kim, K. Fukushima, J. Sly, R. D. Miller, R. M. Waymouth, Y. Y. Yang, J. L. Hedrick, Biomacromolecules 2009, 10, 1460.

[46] T. Govender, T. Riley, T. Ehtezazi, M. C. Garnett, S. Stolnik, L. Illum, S. S. Davis, Int. J. Pharm. 2000, 199, 95.

[47] H. Yu, D. Xia, O. Zhu, C. Zhu, D. Chen, Y. Gan, Eur. J. Pharm. Biopharm. 2013, 85, 1325.

[48] S. Y. Kim, Y. M. Lee, Biomaterials 2001, 22, 1697.

[49] M. Gou, K. Men, H. Shi, M. Xiang, J. Zhang, J. Song, J. Long, Y. Wan, F. Luo, X. Zhao, Z. Qian, Nanoscale 2011, 3, 1558.

[50] W. Xu, P. Ling, T. Zhang, J. Drug Delivery 2013, 2013, 340315.

[51] F. Wang, D. Zhang, O. Zhang, Y. Chen, D. Zheng, L. Hao, C. Duan, L. Jia, G. Liu, Y. Liu, Biomaterials 2011, 32, 9444

[52] R. Savic, L. B. Luo, A. Eisenberg, D. Maysinger, Science 2003, $300,615$.

[53] S. Binauld, M. H. Stenzel, Chem. Commun. 2013, 49, 2082.

[54] R. Hourani, M. Jain, D. Maysinger, A. Kakkar, Chem. Eur. J. 2010, 16, 6164. 